\title{
Folate Biosynthesis - Reappraisal of Old and Novel Targets in the Search for New Antimicrobials
}

\author{
James Swarbrick*,a $^{*}$, Peter Iliades ${ }^{\mathrm{b}}$, Jamie S. Simpson ${ }^{\mathrm{a}}$ and Ian Macreadie ${ }^{\mathrm{c}}$ \\ ${ }^{a}$ Medicinal Chemistry and Drug Action, Monash Institute of Pharmaceutical Sciences, Monash University (Parkville \\ Campus), 381 Royal Parade, Parkville, Victoria 3052, Australia, ${ }^{b}$ The Walter and Eliza Hall Institute of Medical Re- \\ search, $1 G$ Royal Parade, Parkville, Victoria 3050 Australia and ${ }^{c}$ CSIRO Molecular and Health Technologies, 343 \\ Royal Parade, Parkville, Victoria 3052 Australia
}

\begin{abstract}
Folate biosynthesis remains a key target for antimicrobial therapy. Folate is an essential vitamin (vitamin B9) that is required for many one-carbon transfer reactions and is a critical precursor for the biosynthesis of purines, pyrimidines, and amino acids. Unlike higher eukaryotes that scavenge preformed folates, prokaryotic and lower eukaryotic microorganisms are dependent on several enzymes for the de novo biosynthesis of folate. One of these enzymes, dihydropteroate synthase (DHPS), is the target of the first chemically-synthesized antimicrobial agents, the sulfadrugs, which date back to the 1940s. Others are essential enzymes that remain to be explored as drug targets. Resistance to the sulfadrugs rapidly emerges due to the ability of the microbe to alter its susceptibility to the drug by various means. Recently a number of new structures of the enzymes in the pathway has become available. We review the recent literature relating to these targets (the enzymes: GTP cyclohydrolase (GTP-CH); 7,8-dihydroneopterin aldolase (DHNA), 6-hydroxymethyl7,8-dihydropterin pyrophosphokinase (HPPK), dihydropteroate synthase (DHPS), dihydrofolate synthase (DHFS)), their mode of action and how current drugs may modulate this on a structural level. Furthermore, these data advance our understanding of the emergence of drug resistance and may aid efforts and play a major role in the design of new, more effective compounds as antimicrobial agents. To this end we also review the recent literature in the development of inhibitors of these enzymes. Future progress in this key area has the potential to benefit the war against devastating organisms such as drug-resistant Staphylococcus aureus and Plasmodium falciparum.
\end{abstract}

\section{INTRODUCTION}

Effective antimicrobials are essential for the maintenance of our $21^{\text {st }}$ century lifestyle. Without antimicrobials, death rates from simple and common infectious diseases would be high, epidemics would be rampant and advances in surgery and immunosuppressive therapies would amount to nil. Good targets for antimicrobials are essential enzymes (for the microorganism) that are not present in the host organism. Furthermore, it is preferable that the enzyme has a track record as a target for drugs and its properties are well documented. The folate biosynthetic pathway fits the criteria of being an ideal target for antimicrobial therapy and is the focus of this review.

Our review commences with a historical perspective of the clinical application of the sulfadrugs that target folate synthesis to the inevitable rapid spread of antibiotic resistance in several relevant pathogenic organisms. Understanding of resistance is explained at the molecular and structural level of the folate biosynthesis pathway. An insight into the catalytic mechanism and function is provided by virtue of a multitude of structures for all the relevant enzymes often in many catalytic states. Therefore, we describe current strategies that tap into this structural data resource and review structural biology combined with medicinal chemistry, assay technologies, modern structure-based approaches and me-

\footnotetext{
*Address correspondence to this author at the Medicinal Chemistry and Drug Action, Monash Institute of Pharmaceutical Sciences, Monash University (Parkville Campus), 381 Royal Parade, Parkville, Victoria 3052, Australia; Tel: (+61-3) 9903 9543; Fax: (+61-3) 9903 9582;

E-mail: James.Swarbrick@vcp.monash.edu.au
}

thods for inhibitor design. The folate biosynthesis pathway is shown to have considerable untapped potential to be exploited for the rational design of new antibiotics that can slow the onset of resistance and combat current resistance isolates that are threatening epidemics across the world.

\section{HISTORICAL ASPECTS LEADING TO RESISTANCE}

Drug pressure on the folate biosynthetic pathway to date has only occurred on DHPS so it is not surprising that mutations in DHPS, DHPS gene duplication and the confounding effects of DHPS metabolites, pABA or environmentally acquired folates, are the only clinically-verified resistance modalities reported. From the very beginning, sulfonamides were used to treat diverse infections and consequently, resistance has been observed in all circumstances.

Sulfanilamide (the active component of Prontosil - an azo sulfonamide dye) was developed in 1932. Domagk demonstrated that it was capable of protecting mice from lethal streptococcal infections, rabbits from staphlylococcal infections, and in one case, cured an infant from a life-threatening infection. This work led to Domagk being awarded a Nobel Prize in 1939. Prontosil was successfully trialled for the treatment of malaria in 1937 [1] and thousands of sulfonamide/sulfone compounds, collectively called sulfadrugs, have been synthesised and tested since.

The use of sulfonamide and sulfones as antifolates predates the demonstration of their mode of action. As early as 1940 however, pABA was found to antagonize the bacteriostatic action of sulfonamides [2]. Enzymes involved in bacterial folate biosynthesis were identified in the 1960s as were 
the first resistance mechanisms. It was determined that increased pABA and folic acid synthesis could lead to sulfonamide resistance in Staphylococci $[3,4]$.

Sulfonamides were found to act on the folate biosynthetic pathway as competitive (with pABA) inhibitors of DHPS. Furthermore, the sulfonamides tested were more inhibitory in cell-free enzymatic systems than as inhibitors of cell growth indicating limited cell permeability [5]. One year later, E. coli mutants were selected that had mutant enzymes that changed the cell's permeability to sulfonamides [6].

In the 1950s it became evident that the combination of sulfonamides and the 2,4 diaminopyrimidine class of compounds (later shown to be DHFR inhibitors) were more effective than either drug alone to treat malaria patients infected with $P$. falciparum $[7,8]$. The use of sulfonamides as a monotherapy to treat malaria infections was discontinued due to the low efficacy and high toxicity [9-11]. In various studies in the 1960 s, combination therapy proved more efficacious than the traditional anti-malarial (chloroquine) which they replaced owing to emerging parasite resistance [12-16]. However, antifolate resistance to SP (Sulfadoxine / Pyrimethamine) emerged almost immediately following its introduction in 1967 in Thailand [17].

The dogma until recently was that sulfonamides exerted all their effects by competing with pABA to deplete the intracellular folate-cofactor pool, thus starving the cell. The sulfa-pterin analog diffused out of the cell and was of no consequence to the growth of bacteria exposed to it [18]. However, later work by Patel and colleagues showed that in Saccharomyces cerevisiae, the sulfa-containing folate analogs were growth inhibitory [19].

\section{ANTIFOLATE DRUG RESISTANCE MECHANISMS}

Numerous antifolate resistance mechanisms have been reported. A plethora of reports have described multiple amino acid mutations, insertions and duplications in DHPS that confer drug resistance to sulfonamides from many organisms. Mutant DHPS genes have been detected in pathogens where resistance was acquired by horizontal transfer [20]. DHPS resistance elements have remained long-lived even when sulfonamide pressure has been withdrawn owing to drug pressure exerted by other drugs [21]. Gene amplification was demonstrated as a potential sulfonamide drug resistance mechanism in model systems [22, 23] and recently shown to be a clinically valid resistance mechanism following chromosomal amplification of genetic elements encoding DHPS in S. agalactieae [24]. The competing effect of increased levels of the DHPS substrate pABA was shown to confound the effects of sulfonamides [2] both clinically and in model systems [25] as was the acquisition of environmental folates [26, 27]. Drug resistance mutations have long been known to confer a fitness compromise. It has been shown in both model systems [28-30] and clinically [31, 32] that compensatory mutations or adaptation mechanisms are capable of facilitating enzymatic improvements or altered regulation of metabolic pathways to counter the fitness compromise.

\section{DISEASES TARGETED BY ANTIFOLATES}

Sulfonamides have been used to treat a large number of fungal, bacterial and parasitic infections including; Pneumo- cystis pneumonia, malaria, Pneumococcal pneumonia, urinary tract infections, candidiasis, tuberculosis, leprosy, meningitis, toxoplasmosis and many others. As with most antibiotics which function as anti-metabolites, resistance evolved rapidly making these compounds of limited utility and consequently reducing man's armoury of effective antibiotic countermeasures. Some drug resistant pathogens that are of significant consequence to human health world-wide will be reviewed.

\section{FUNGAL PATHOGENS}

\section{Pneumocystis jirovecii (Formerly carinii)}

Pneumocystis jirovecii is a major opportunistic pathogen that results in Pneumocystis pneumonia (PCP) of AIDS patients and immunocompromised individuals. It accounts for $40 \%$ of all AIDS-defining conditions and is the major cause of mortality of children with AIDS in Africa [33, 34]. Clinically, PCP has been treated with antifolates including combination therapy with sulfamethoxazole (SMX) and trimethoprim (TMP) as the preferred first-line treatment [35]. In $P$. jirovecii, however, there is some evidence to suggest that TMP is ineffective and that such treatment is actually sulfamethoxazole monotherapy $[36,37]$.

The widespread use of sulfamethoxazole-trimethoprim (SMX-TMP for prophylaxis against $P$. jirovecii pneumonitis in HIV-infected patients) has been implicated as the cause of the increase in SMX-TMP -resistant bacteria [38]. Several studies have demonstrated point mutations in the $P$. jirovecii DHPS gene and have found an association between the use of sulfonamide or sulfone drugs for $P$. carinii prophylaxis and DHPS mutations [39, 40] but not in the DHFR gene [41].

The failure of prophylaxis and treatment of PCP patients has been associated with mutations in DHPS (similar to those that confer sulfa resistance in other organisms) in a large number of epidemiological studies [33-35, 39-47]. However more direct evidence demonstrating that such mutations confer resistance in $P$. jirovecii only recently emerged [48, 49] using models systems. In fungi, mutations involved in resistance to sulfonamides are shown in Table $\mathbf{1}$.

Importantly, in the model studies of $P$. jirovecii DHPS mutations, it was observed that mutants having two amino acid substitutions were initially compromised for growth due to an increased requirement for pABA. Prototrophs that could grow in the absence of pABA could be isolated via continual passage on low pABA medium [28]. As a result these double mutants were found to be capable of improved growth vigor and consequently increased sulfa drug resistance indicating an adaptive response to the initial growth compromise presumably conferred by the DHPS mutations [28]. This suggested that the DHPS mutations resulted in decreased enzyme activity thus reducing folate synthesis. The observed adaptation to low pABA medium implicated pABA up-regulation with sulfamethoxazole resistance mutations. Thus increased pABA synthesis probably reflects an adaptive response that compensates for the reduced pABA binding affinity by the double amino acid substitutions at the catalytic site of DHPS. This would fit with previous observations in other model systems [32]. Adaptation to sulfonamide resistance in Neisseria meningitidis may have required com- 
Table 1. Changes in P. jirovecii and S. cerevisiae DHPS that are Associated with Sulfonamide Resistance. Numbering is from the First Methionine of the Primary Translation Product

\begin{tabular}{|c|c|c|}
\hline \multirow{2}{*}{ Allele Name } & \multicolumn{2}{|c|}{ Amino Acid Position in DHNA-HPPK-DHPS } \\
\cline { 2 - 3 } & \#557 in S. cerevisiae; \#517 in P. jirovecii & \#559 in S. cerevisiae; \#519 in P. jirovecii \\
\hline \hline Wild Type & $\mathrm{T}$ & $\mathrm{P}$ \\
\hline VRS & $\mathrm{V}$ & $\mathrm{S}$ \\
\hline ARS & $\mathrm{A}$ & $\mathrm{S}$ \\
\hline TRS & $\mathrm{T}$ & $\mathrm{S}$ \\
\hline ARP & $\mathrm{A}$ & $\mathrm{P}$ \\
\hline
\end{tabular}

pensatory changes to retain enzyme function: kinetic analysis of dihydropteroate synthases from $N$. meningitidis expressed in a knockout mutant of Escherichia coli [32]. Similar observations were made by Schrag and Perrot who noted an adaptive response that resulted in secondary mutations to compensate for the fitness compromise conferred by the primary mutations that led to drug resistance [29].

Conclusive evidence that the DHPS mutations resulted in sulfa drug resistance emerged following the cloning of the trifunctional $P$. jirovecii DHNA-HPPK-DHPS [50] genes and their heterologous complementation in a DHPSdisrupted E. coli host strain [28]. Site-directed mutagenesis of the $P$. jirovecii trifunctional DHNA-HPPK-DHPS genes [48] to reverse engineer the mutations suspected by epidemiological data to cause drug resistance provided an assay method that permitted a direct assessment of sulfa drug resistance. Thus the mutations observed clinically (T517A and P519S) in the PjFAS genes were found to result in a threefold increase in sulfamethoxazole resistance relative to the wild type clone and furthermore conferred significant cross resistance to a range of sulfadrugs.

\section{PROTOZOAL PATHOGENS}

\section{Plasmodium falciparum}

Malaria is one of the primary causes of infant mortality in the developing world and is caused largely by the proto- zoan parasite Plasmodium falciparum. It accounts for $80 \%$ of malaria infections and $90 \%$ of deaths estimated to be between 1-3 million per year of the 500 million infections worldwide [51]. The largest mortality and morbidity burden is suffered in sub-Saharan Africa, and in particular by infants. To date, malaria has been targeted therapeutically and preventatively with numerous antimalarials including chloroquine (quinines), artemisinin, atovaquone, doxycline and antifolates. All have led to resistance and multiple drug resistance is common in many parts of the world where malaria is endemic.

$P$. falciparum drug resistance has spread very rapidly after the introduction of antimalarial therapeutic and prophylaxis measures in Asia, South America and Africa. Mutations that cause antifolate resistance have been found in DNA sequences of DHPS associated with resistance to sulfadoxine [52-56]. In DHPS the acquisition of multiple point mutations (Table 2) has been shown to increase sulfonamide resistance $[55,57]$. The relative contribution of the mutations has been shown to be predictive of treatment failure in particular combinations [58]. For example, E540 was a strong predictor of treatment failure as was DHFR mutant R59 in combination with DHPS E540.

Alignments of $P$. falciparum DHPS with other DHPS enzymes indicate that changes that result in sulfa drug resistance lie in regions that are close to the site of catalysis. It

Table 2. Changes in P. falciparum DHPS that are Associated with Sulfadoxine (SDX) Resistance. Numbering is from the First Methionine of the Primary Translation Product

\begin{tabular}{|c|c|c|c|c|c|c|}
\hline \multirow{2}{*}{ Isolate } & \multirow{2}{*}{ SDX Response } & \multicolumn{5}{|c|}{ Amino Acid Position } \\
\cline { 3 - 6 } & & $\mathbf{4 3 6}$ & $\mathbf{4 3 7}$ & $\mathbf{5 4 0}$ & $\mathbf{5 8 1}$ \\
\hline \hline Wild-type & Sensitive & S & A & K & A \\
\hline 3D7 & Resistant & G & G & E & \\
\hline TN-1 & Resistant & G & G & G & G \\
\hline K1 & Resistant & G & G & G & S \\
\hline W2 & Resistant & F & G & G & T \\
\hline V1/S & Resistant & F & & \\
\hline
\end{tabular}


would appear that changes involved in DHPS associated with sulfa drug resistance lead to reduced affinity of the sulfa drug for DHPS.

Resistance to antifolates by eukaryotes can be further achieved via acquisition of environmental (exogenous) folates via active folate-specific transporters $[59,60]$. It has been demonstrated that antimalarial therapy using antifolates can be significantly compromised by the concomitant dietary supplementation of folic acid [26, 27]. In addition, increased expression levels of DHPS increase or decrease sulfa drug resistance depending on whether pABA is high or low, respectively $[22,28]$. pABA overexpression as a potential mode alleviating the inhibitory action of sulfonamides has been demonstrated in vivo using a $S$. cerevisiae model [25]. Drug resistant mutants to DHFR inhibitors (Pyr) were found to be selected when the in vivo concentration fell below the effective therapeutic concentration [61, 62].

\section{BACTERIAL PATHOGENS}

Multi-drug resistance has eventuated as a particular problem for the treatment of urinary tract infections. $25-80 \%$ of such infections were characterised as being multi-drug resistant by 1975 [63]. These resistant isolates showed sulfonamide resistance with Minimum Inhibitory Concentration (MICs) 100-1000 fold higher than sensitive strains. The resistance can be chromosomally encoded and include a single F28L mutation in DHPS [64] or can be carried on horizontally transmissible plasmids. These resistance plasmids have persisted undiminished despite the prolonged withdrawal of selection pressure following formal introduction of prescribing restrictions on co-trimoxazole, [65, 66].

\section{Neisseria meningitidis}

Neisseria meningitidis is a gram-negative diplococcal bacterium that infects and inflames the protective membranes covering the central nervous system resulting in the rapid progression from fever, headache and neck stiffness to coma and death in $10 \%$ of patients or higher if left untreated.

The massive use of sulfonamides for both prevention and treatment of meningococcal disease $[67,68]$ led to the isolation of resistant strains of Neisseria meningitidis as early as 1937 [69], only a couple of years after the discovery of this class of drugs. Resistance has been shown to be mediated by altered forms of the chromosomal dhps gene [20,70]. As a result the World Health Organisation now states "Although oral cotrimoxazole (trimethoprim sulfamethoxazole) is inexpensive and has good CSF penetration, sulfa resistant strains have become common and sulfadrugs are not recommended unless sulfa sensitivity testing has been done. In unfavourable conditions, the drug of choice is oily chloramphenicol" [71].

Two DHPS mutations F31L and G194C were shown by MIC determinations to effect resistance [72] as well as $\mathrm{Km}$ and the $\mathrm{K} i$. A third mutation (P84S) did not have any obvious effect on the resistance phenotype, however analysis of its enzyme kinetics showed altered $\mathrm{Km}$ thus acting as a compensatory mutation for the first two mutations which mediate sulfonamide resistance.

\section{Streptococcus pneumoniae}

Streptococcus pneumoniae, or pneumococcus, is a Grampositive, alpha-haemolytic diplococcus bacterium and is a significant human pathogen recognized as a major cause of pneumonia worldwide. S. pneumoniae is the most common cause of acute respiratory infections in adults and children which infects an estimated 2.6 million children under five years of age annually. Pneumococcus causes over 1 million of these deaths, most of which occur in developing countries, where pneumococcus is probably the most important pathogen of early infancy [73]. Antifolates are no longer used, due to resistance conferred by mutations / insertions encoded on chromosomal DHPS acquired through horizontal transfer which effected $\mathrm{K} m$ for pABA and $\mathrm{K} i$ for sulfonamides. [74, 75]

\section{SUMMARY OF SULFA DRUG RESISTANCE}

Numerous drug resistance mechanisms have emerged in all cases where sulfonamides have been used, and as is the case for all antibiotics this is not a new phenomenon. Resistance has emerged due to overprescribing, ineffective use of synergistic compounds, poor patient compliance with drug regime and the use of the drugs in the animal industry. Antifolates however have proved to be successful (until the emergence of resistance) in treating a broad range of infection thus validating the pathway as a source of important target. The folate biosynthetic pathway has multiple unique enzymes to prokaryotes and lower eukaryotes that recognize pterin-like molecules and as a result there could be potential for cross reactive compounds within the pathway. Such cross-reactivity could potentiate the effectiveness of antifolate compounds and possibly act in a powerful and synergistic fashion similar to the synergism seen between sulfadrugs and DHFR inhibitors.

\section{FOLATE BIOSYNTHESIS PATHWAY}

Folate is an essential metabolite required for many onecarbon transfer reactions and is a critical precursor for the synthesis of purines, pyrimidines and amino acids. Prokaryotic and lower eukaryotic micro-organisms are dependent on several enzymes for de novo folate biosynthesis (Fig. 1). In contrast, higher eukaryotes (including mammals) do not possess these enzymes and are entirely dependent on folate derived from their diet and active folate transport mechanisms. Consequently enzymes of the de novo pathway may provide ideal targets for therapeutic intervention for treatment of infections and serious diseases and infections caused by prokaryotic and lower eukaryotic pathogens.

\section{Targets from the Folate Biosynthesis Pathway}

The de novo folate biosynthesis pathway comprises six committed enzymes GTPCH, a NUDIX pyrophosphatase, DHNA, HPPK, DHPS and DHFS that collectively converts GTP into dihydrofolate with the incorporation of pABA and glutamates (Fig. 1). The inactive dihydrofolate from this pathway is subsequently reduced into the active form tetrahydrofolate via DHFR. This step is not part of the de novo pathway per se, but rather is part of the subsequent folate utilization step. DHFR is common to mammalia, protozoa and bacteria. Nevertheless, DHFR active sites are both highly conserved within each of these three classes and also subtly different between mammalia, protozoa and bacteria. Consequently, DHFR is a successful target for the competitive inhibitors methotrexate, trimethoprim and pyrimethamine, which are in use for cancer therapy, bacterial and pro- 
<smiles>Nc1nc2c(ncn2[C@@H]2O[C@H](COP(=O)([O-])OP(=O)([O-])OP(=O)([O-])[O-])[C@@H](O)[C@H]2O)c(=O)[nH]1</smiles>

guanine triphosphate<smiles>COP(=O)(OC)OP(=O)(OC)OP(=O)(OC)OCC(O)C(O)C1=Nc2c(nc(N)[nH]c2=O)NC1</smiles>

7,8-dihydroneopterin triphosphate

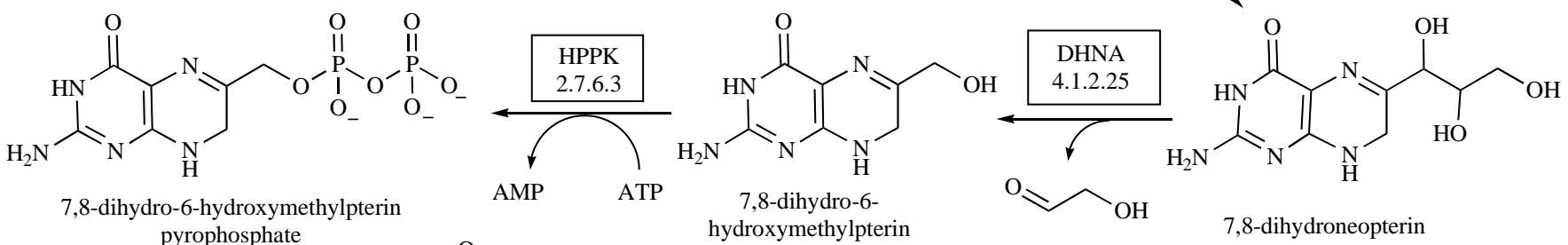

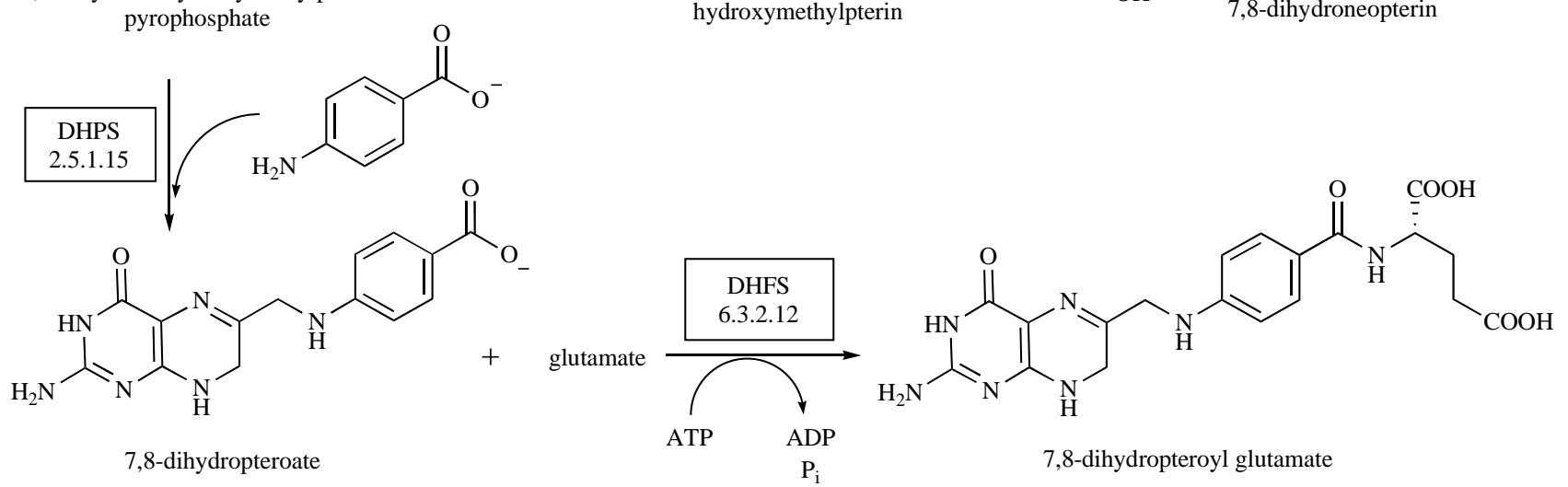

Fig. (1). The folate biosynthetic pathway in plants and microbes.

tozoal infections respectively. As described, the existing antifolate drugs tend to be synergic cocktails of a DHPS inhibitor, (e.g. sulfadioxine, sulfalene or dapsone) with the DHFR inhibitor, pyrimethamine.

\section{GTP Cyclohydrolase}

The first enzyme, GTP-CH, catalyses the conversion of GTP into 7,8-dihydroneopterin triphosphate using two molecules of GTP. Although the enzyme is found in a wide range of prokaryotic and eukaryotic species, dihydroneopterin triphosphate is either processed into tetrahydrofolate or, in the case of animals lacking the biosynthesis pathway, is converted into tetrahydrobiopterin. However the pterin binding site is very well conserved across all species and thus probably not ideally suited to antimicrobial development. close structural mimics of the reaction substrate or product. For example, although the monocyclic 2,4-diamino-6-hy droxypyrimidine (Fig. 2, compound 1), was thought to be an inhibitor of GTP cyclohydrolase. Xie et al., [76] recently demonstrated that this compound actually acts through an indirect mechanism involving binding to GFRP (GTP-CH feedback regulatory protein), rather than direct inhibition.

\section{Removal of Pyrophosphate - the Mystery Solved}

The removal of the triphosphate in the second step seems to occur via two phosphatases, one removing pyrophosphate and the other a phosphate. The identification of a specific enzyme committed to the pyrophosphatase function was until recently a mystery. Nevertheless, an $E$. coli NUDIX hydrolase was confirmed to convert DHNTP into DHNMP with the loss of pyrophosphate in vivo and the structure has been solved by X-ray analysis [77]. In a knockout strain, the level of folate dropped considerably, and was restored with the NUDIX plasmid complementation, showing specificity of this enzyme. Despite this observation, there was no reduction in growth rate compared to the wild type, suggesting that conversion into DHNMP can take place via other nonspecific enzymes or in a non-enzymatic manner. Accordingly, the NUDIX enzyme may not represent an attractive drug target. No enzyme to date that removes the final phosphate has been identified and the reaction most likely is mediated by non-specific phosphatases.

The four remaining enzymes of the folate pathway, DHNA, HPPK, DHPS and DHFS represent either current targets (DHPS) or potential sources for drug intervention. Therefore considerable attention has been given to these enzymes from sequence through to structure to both understand and interfere with the catalytic function, and to rationalize a molecular basis behind antibiotic resistance.

\section{Formation of HP - DHNA}

DHNA catalyses both the epimerization of 7,8-dihydroneopterin (DHNP) to 7,8-dihydromonapterin (DHMP) and the conversion of DHNP or DHMP to 6-hydroxymethyl-7,8- 
<smiles>Nc1cc(=O)[nH]c(N)n1</smiles>

1<smiles>Cn1cnc2c(=O)[nH]c(N)nc21</smiles><smiles>Nc1nc2c(c(=O)[nH]1)N=C(CO)CN2</smiles>

2<smiles>CCOC(=O)c1cnc(N)[nH]c1=O</smiles><smiles>NC(=O)C1=Nc2c(nc(N)[nH]c2=O)NC1</smiles>

3<smiles>CN1C(=O)c2[nH]c(N)nc2N(C)C1O</smiles><smiles>Nc1nc(-c2ccccc2)c(Br)c(=O)[nH]1</smiles>

7<smiles>Nc1nc2nn(-c3cccc(C(=O)O)c3)nc2c(=O)[nH]1</smiles>

8<smiles>Nc1nc2nn(-c3cccc(C(=O)NCc4cc(Cl)cc(Cl)c4)c3)nc2c(=O)[nH]1</smiles>

Fig. (2). Structures of inhibitors of GTP-CH and DHNA.

dihydropterin (HP) with the generation of glycoaldehyde (Fig. 1). The DHNA structure from three organisms has been solved by X-ray crystallography (S. aureus [78], S. pneumonia [79] and M. tuberculosis [80]). Much information has been derived using the $S$. aureus enzyme from structures of the holoenzyme [80] and in complex with the product HP [81], and substrate analogs, neopterin (NP) and monopterin (MP) [81], and product [80].

The epimerization mechanism proceeds through an active site lysine that functions as a general base and a bound water as a proton donor. Four structural snapshots along the catalytic trajectory from the X-ray analysis of $S$. aureus DHNA allow a detailed structural understanding of this mechanism.

Generally speaking, DHNA holoproteins are octameric in the absence or presence of substrate which sits between the protomers (Fig. 3a). For example, the oligomeric state is supported by sedimentation equilibrium studies of $E$. coli and Haemophilus influenza enzymes [82]. Interestingly, the structure of DHNA from M. tuberculosis is tetrameric in the "apo" enzyme and is octameric with product. Four helices occupy the substrate position in the inactive tetrameric enzyme. Hence, a substrate-induced conformational change has to take place which results in the displacement of these helices and the formation of the active octamer. This substrateinduced oligomerisation was supported using sedimentation equilibrium measurements [80]. Kinetic analysis of substrate binding gave a Hill coefficient of 2 indicating positive cooperativity and thus a substrate driven model for the formation of the octamer was proposed. The model involved an initial binding to a single low affinity tetrameric site followed by subsequent binding to the higher affinity octomeric sites. In this way DHNA from M. tuberculosis is allosterically regulated through oligomerisation. This unique characteristic of the M. tuberculosis enzyme was explained based on structural differences within the tetramer-tetramer interface and the pterin binding pocket as compared to the other DHNA structures.

It has been shown in mammals that 7,8-dihydroneopterin acts as a powerful antioxidant by inhibiting low density lipoprotein oxidation, peroxyl radical formation and super-oxide generation. Hence the authors propose that, under stressful conditions, the inactive tetramer switches the role of the substrate to an antioxidant thereby protecting $M$. tuberculosis from the damaging effects of hydrogen peroxide from the host. When oxidative stress diminishes and the levels of substrate rises further, the octameric species forms and folate biosynthesis proceeds in the usual manner.

The malaria parasite, $P$. falciparum, is a little unusual in that it contains both a folate biosynthesis and a folate scavenging pathway, both of which are essential to the organism for healthy growth. Interestingly, the folate biosynthesis pathway lacks a DHNA gene but is otherwise identical to other folate synthesizing organisms. Recently an ortholog of 6-pyruvoyltetrahydropterin synthase (PTPS), an enzyme from the biopterin pathway, was identified [83]. PfPTPS takes the product of GTP cyclohydrolase and catalyses the formation of 6-pyruvoyl-5,6,7,8-tetrahydropterin and 6hydroxmethyl-7,8-dihydropterin (the substrate of HPPK), thus performing the function of the missing DHNA. The PfPTS otholog differs by a substitution of a conserved active site cysteine to a glutamate which acts as a nucleophile during catalysis. This mutation is conserved in several other plasmodium species as well as $T$. gondii. Crystal structures of PTPS from P. vivax and P. falciparum have been deposited (PDB entries 2AOS and 1Y13 respectively) as well as those from $P$. aeruginosa, $P$. horikoshi, C. elegans and $R$. norvegegicus.

\section{DHNA Inhibitors}

Early reported inhibitors of dihydroneopterin aldolase were dihydropterins closely related to substrate and product 


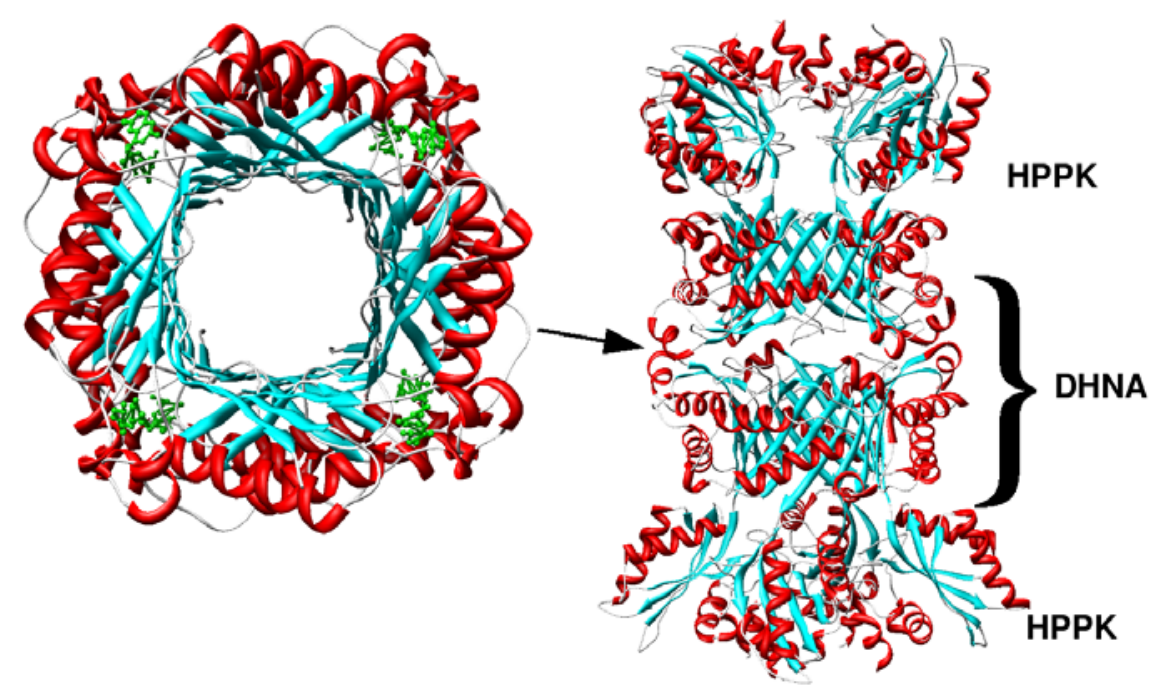

Fig. (3). Left: Top view looking down through the pore of a ribbon representation of the octomeric structure of DHNA in complex with the product HP in green. Right: Orthogonal view showing the assembly of the bifunctional DHNA-HPPK enzyme from S. pneumoniae.

structures, including the alcohol 2 and the amide $\mathbf{3}$ (Fig. 2), reported by the Merck group [84]. These compounds had $\mathrm{IC}_{50}$ values with the enzyme of 1 and $5 \mu \mathrm{g} / \mathrm{mL}$, respectively.

More recently, DHNA from $S$. aureus has been the focus of a very elegant high throughput crystallographic screening study for lead compounds (crystalLEAD) [85]. A library of 10,000 compounds was screened to detect initial hits, and these included methylguanine (4), pyrimidines 5 and $\mathbf{6}$ and aminopurine 7 (Fig. 2). A subsequent round of screening used a focused library based on the observed three-point hydrogen-bonding motif common to the initial hits. Interestingly, none of these inhibitors gave structures from soaking experiments but co-crystallisation was successful in all cases. This is consistent with the observation of sigmoidal inhibition curves and the notion of a conformational shift taking place during ligand binding in a cooperative manner.

This smaller targeted library led to the identification of triazole 8, which displayed an $\mathrm{IC}_{50}$ of $1.5 \mu \mathrm{M}$. A focused library based on carboxylic acid $\mathbf{8}$ was synthesized to evolve fragments to potentially fit into an extended nearby hydrophobic binding groove using simple amide linkage chemistry. The groove displayed a range of sizes in the different lead complexes, consequently both large and small hydrophobic substituents were added and gave a number of more potent inhibitors, the most potent of which (dichlorobenzyl substituted 9, Fig. 2) showed an $\mathrm{IC}_{50}$ of $69 \mathrm{nM}$. Although the compounds showed good in vitro inhibition, none showed in vivo activity when tested against several pathogens and were therefore not suitable as an antimicrobial. Furthermore, none was active against a hypersusceptible permeability mutant and Acr- efflux pump mutants of both $E$. coli and $H$. influen$z a$. Similarly, they were also not active in the presence of permeability-enhancing agents and none inhibited bacterial uptake of radiolabelled pABA. This suggests that permeability is not the issue. It was proposed that inhibitors were inactivated by either intracellular enzymes or by non-specific binding to intracellular membrane proteins both of which could cause this lack of activity in vivo. An alternative possibility put forward is that the intracellular concentration of the DHNA substrate can be high relative to the $\mathrm{K}_{\mathrm{m}}$ of the enzyme in which case the inhibitors would have to be significantly more potent to be effective.

This study is the most elegant and detailed structurebased effort published to date in the design of antimicrobials from the enzymes of the de novo folate biosynthesis pathway. It showcases the utility of the CrystaLEAD method to screen and deliver highly potent inhibitors. It reveals the shortcomings of ligand soaking over co-crystallisation to overlook potential lead compounds when ligand-induced conformational shifts occur. Conformational motion such as this may be very pertinent given the significant range of loop motions encountered in all the structures discussed herein. Finally, despite compound 9 being a good in vitro inhibitor, this work shows that elements other than structural design will have to be overcome before a suitable inhibitor can be a good in vivo lead compound.

\section{Pyrophosphoryl Transfer - HPPK}

HPPK catalyzes the transfer of pyrophosphate from a bound ATP to 6-hydroxymethyl-7,8-dihydropterin (HP), Fig. (1). Over twenty HPPK structures have been deposited from five different species to date e.g. E. coli [86], $H$. influenza [87], S. pneumoniae [79], and S. cerevisiae [88], Y. pestis [89]). Those from $S$. cerevisiae and $S$. pneumoniae have been solved as bifunctional enzymes with either DHPS or DHNA respectively. Generally speaking, there is little biophysical or structural evidence to suggest that the biological functional unit of HPPK is anything other than a monomer.

High sequence identity (33-61\%) combined with active site structural similarity (Fig. 4) for the determined structures, suggests that broad spectrum anti-infective agents can be developed. The $E$. coli enzyme is both small (153 residues) and has a high thermal stability [90]. Accordingly, a host of both NMR and X-ray structures has been deposited, largely from the work out of the H. Yan group, providing a convenient system to study the molecular basis behind pyrophosphoryl transfer and establishing a platform for structurebased drug discovery strategies. 


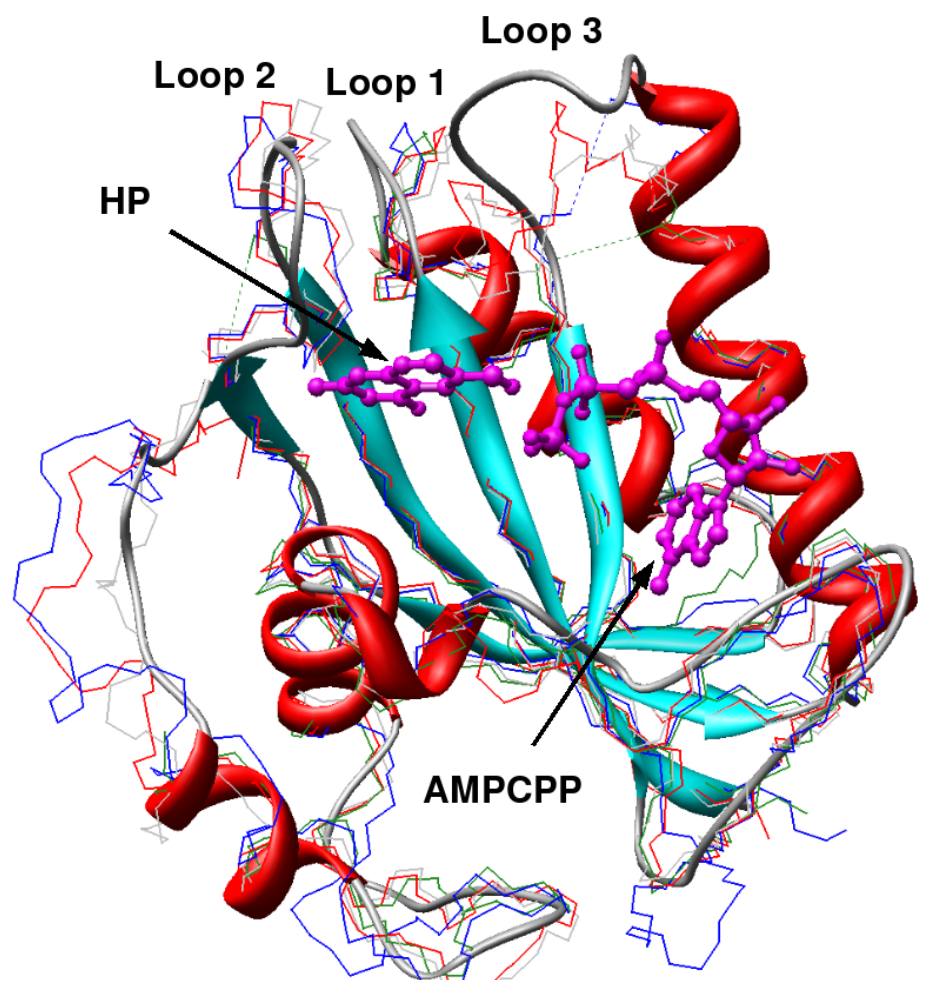

Fig. (4). Superposition of E. coli (grey), H. influenza (red), S. pneumoniae (green), S. cerevisiae (blue) and $Y$. pestis HPPK structures. A ribbon representation of the fold is drawn along the $Y$. pestis structure. The bound HP and the ATP analogs are displayed as ball and stick.

It is notable that in Plasmodium species, large inserts are found in HPPK sequences. Although no structure of HPPK has been elucidated in $P$. falciparum, a model has been derived based on the HPPK-DHPS structure in yeast [88] to understand structural aspects of the bifunctional HPPK-DHPS enzyme and the role, if any, of the two large insertions in the HPPK sequence. Most of the 23 conserved active site residues [90] are conserved, aiding model building and revealing a core structure very similar to other bacterial HPPK enzymes. Some evidence based on molecular dynamics simulations was put forward for the role of loop 1 to stabilize the bifunctional assembly.

The structure of the active site has been well characterized from a range of substrate, substrate analogue and product complexes [86, 90-97]. The structure comprises a threelayered $\alpha \beta \alpha$ fold which creates a valley some $26 \AA$ long, $10 \AA$ wide and $10 \AA$ deep. Much understanding has evolved from $\mathrm{X}$-ray structures in complex with HP and the nonhydrolysable ATP analogue MgAMPCPP. The pterin and ATP are fixed within their sub-sites either end of the valley by a multitude of hydrogen bonds and they interact with a total of 26 residues, 13 of which are conserved. From the structures, an in-line single displacement mechanism with associative character in the transition state has been proposed.

The studies on the E. coli system show a range of loop motions that surround the active site. Interestingly, highly conserved side chains on loop 3 (L3) appear to point away from the active site in the apo structure but come into play during a series of large loop motions during the cycle. Thus loop dynamics (L1, L2 and L3, Fig. 4) are shown to be an integral part of the catalytic mechanism. Loop L3 for example has to open up twice, moving up to $20 \AA$ and $28 \AA$ from the apo position during the cycle and repositions critical arginine side chains in the process. All three critical loops seal the active site for chemical transformation to occur. Within the active site only the adenosine binding site is rigid which is responsible for the observed high specificity. For example the binding of MgGTP is 260-fold less than MgATP [90]. As mentioned, loop 3 is critical for product release, but is not necessary to bind ATP. Its role has been investigated elegantly from X-ray and biochemical methods using a loop deletion [95]. From thermodynamic and transient kinetic data, the full reaction trajectory has been established [96], in which HPPK goes through six distinct steps and X-ray structures are available for each intermediate.

NMR spectroscopy is an invaluable tool to investigate loop dynamics in enzymes. In an NMR study the three loops of the binary complex of HPPK-AMPCPP were shown to assume multiple conformations [98] based on the observation of multiple resonances for the loop residues, although multiple resonances are often observed when a proline is in the loop, as in loop 3, due to the cis - trans interconversion in slow exchange on the NMR time scale. In the ternary complex HPPK-PPK-AMPCPP-DMHP, only one set of NMR signals was observed suggesting that binding of the second substrate shifts the multiple conformations of the binary complex to a single "fixed" conformation during active site closure. 
Although an induced fit model is implied based on X-ray 'snapshots' of almost all stages in the cycle, the NMR data favour an equilibrium conformational model, typical of enzymes [99]. The combined NMR and X-ray approach is optimal to characterize both motions and precise structural details in small enzymes.

HPPKs are generally monomeric in nature, however, a recent $\mathrm{X}$-ray structure from $Y$. pestis (the causative agent of bubonic, pneumonic and septicaemic plagues) [89] shows that the enzyme crystallises as a head to head dimer. In this, the ligands are in close contact with each other and a C2 symmetry operation relates the two practically identical monomers. Although other biophysical methods were not sought to report on this rather unique oligomeric state, a reduced surface area $\left(2851 \AA^{2}\right)$ compared to typical $\left(3900 \AA^{2}\right)$ for dimers of this size was noted and this casts doubt on the catalytic relevance of the dimer. Studies from the same group (either solution NMR or biophysical methods) are hopefully in progress to resolve this rather interesting anomaly.

\section{HPPK Inhibitors}

Bermingham et al. [100] reported that the pterin substrate did not bind in the absence of ATP or a stable analogue (AMPCPP, 10) (Fig. 5), and showed that the fluorescent derivative 11 bound similarly to ATP, shedding further light on the catalytic cycle. Both analogs (10 and 11) were competitive inhibitors with respect to ATP. Shi et al., [92] reported the interesting bifunctional molecules (12 and 13), which, although not transition state mimics, consist of both ATP and the pterin substrates linked through phosphates. IC $_{50}$ values of $1.27 \mu \mathrm{M}$ and $0.44 \mu \mathrm{M}$ were found for 12 and $\mathbf{1 3}$, respectively. Compound 13 was 116 and 76 times more potent than MgADP and 6-hydroxymethylpterin respectively. Similarly, ester 12 was 12 and 7 times more so and $\mathrm{MgHP}_{2} \mathrm{~A}(\mathbf{1 2 a})$ had no detectable affinity. Hence, linker length is very important

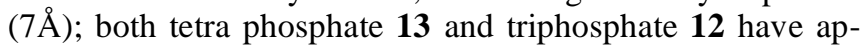
proximately the correct length linkers, albeit with fewer favourable hydrogen bonds in the latter, while the corresponding bis-phosphate linked compound (12a) is too short to connect the pterin and ATP sub-sites. Crystallographic studies shows inhibitor $\mathbf{1 3}$ occupies both the ATP and pterin binding pockets, and causes conformational changes.

Thanks to a range of structural, mechanistic and dynamic data, the stage is set for HPPK to shine as a new player to assist in the design of novel inhibitors of the de novo folate pathway.

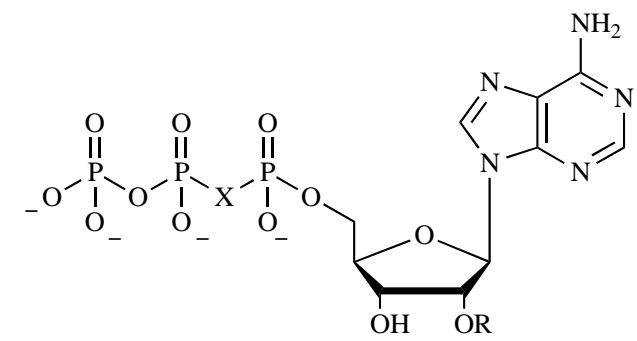

$10 \mathrm{R}=\mathrm{H}, \mathrm{X}=\mathrm{C}$

$11 \mathrm{R}=N$-methylanthraniloyl, $\mathrm{X}=\mathrm{O}$

\section{Old Target with New Potential - DHPS}

DHPS catalyses the conversion of 6-hydroxymethyl-7,8dihydropterin-pyrophosphate (DHPP) and pABA to 7,8dihydropteroate (Fig. 1). It is the target for the well known antimicrobial and antifungal 'sulfadrug' class of compounds that act as competitive inhibitors and dead end substrate ana$\log$ s of pABA. The structures of DHPS from five different organisms (E. coli [101], S. aureus apo form [102], M. tuberculosis [103], S. cerevisiae [88] and B. anthracis [104]) have been solved using X-ray crystallography. Structures include holoenzymes and binary complexes with pterin substrate, product analog and 6-methylamino-5-nitroisocytosine (MANIC 14) (Fig. 6), a pterin-like inhibitor. A binary pABA complex or pABA analog has not yielded crystals, which is consistent with kinetic data [105] that showed the pABA site assembly can only take place subsequent, and in addition to, the binding of the pterin moiety. Functional units are homodimers that display a classic $(\alpha / \beta)_{8}$ TIM barrel fold which is well conserved over all structures (Fig. 6). Each monomer is approximately $30-35 \mathrm{kDa}$ and a structure superposition reveals a highly conserved pterin binding pocket located deep towards the centre of the barrel. In contrast, the pABA site is situated in the variable loop region at the $C$-terminal pole and is seemingly more exposed and mobile [104]. In total 15 structures containing substrate and/or product analogs have been solved to date.

Recently, five structures of DHPS from B. anthracis have been determined [104] in a variety of states along the catalytic cycle, including substrate, a bound pterin-like inhibitor, MANIC and a product analogue (pteroic acid). The work greatly advances the understanding of the catalytic mechanism and describes the architecture of the pterin and the pABA site, nestled within the loops.

Loop motions are critical for function in DHPS. During the cycle, a conserved arginine sidechain on loop 2, that was bound in the pterin site, is withdrawn from the barrel core to allow the ligand to bind (see Fig. 7). As part of this process loop 1 moves into the active site and conserved aspartates and asparagines interact with the phosphate binding site and assemble the pABA channel. The authors further allude to details of the transition state geometry, a desirable quality for drug discovery, in which a potential for shuffling of the $\alpha$ phosphate into tight binding $\beta$ pocket was rationalized. This shuffling would both impart strain on the bond to be cleaved and also optimize the $S_{N} 2$ geometry, facilitating the reaction.<smiles>CC(C)(OP(=O)(O)OC[C@H]1O[C@@H](n2cnc3c(N)ncnc32)[C@H](O)[C@H]1O)c1cnc2nc(N)[nH]c(=O)c2n1</smiles>

Fig. (5). Inhibitors of HPPK. 
<smiles>CNc1nc(N)[nH]c(=O)c1[N+](=O)[O-]</smiles>

14<smiles>[R]c1cc([R])cc(NS(=O)(=O)c2ccc(N)cc2)c1</smiles><smiles>Nc1ccc(P(=O)(O)O)cc1</smiles>

19<smiles>COc1cc(Cc2cnc(N)nc2N)cc(OCC(=O)NS(=O)(=O)c2ccc(N)cc2)c1OC</smiles>

20<smiles>[R]c1cc(N)ccc1S(=O)(=O)c1ccc(NCCCOc2c(OC)cc(Cc3cnc(N)nc3N)cc2OC)cc1[R]</smiles>

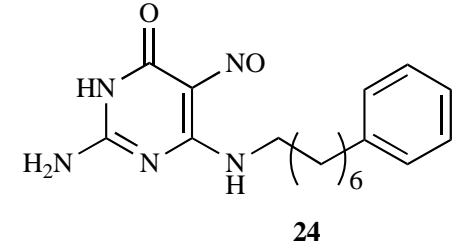

24<smiles>Nc1nc(NCCCNc2ccc(C(=O)O)cc2)c([N+](=O)[O-])c(=O)[nH]1</smiles>

Fig. (6). Structures of DHPS inhibitors.

\section{DHPS and Sulfonamide Resistance}

Owing to the flexible and exposed nature of the pABA binding loop, DHPS can withstand a range of mutations without severely compromising the structural integrity or catalytic viability of the protein. In this manner, mutations in loops 2 and 5 confer sulfonamide resistance (Fig. 7). The Bacillus anthracis structure in complex with pteroic acid identifies the much awaited pABA site, nestled within the flexible loops. It thus reveals a plausible rationale behind the rapid onset for the emergence of resistant isolates to the sulfadrugs.

An interesting proposal, [103, 104] is that the highly conserved pterin site, in contrast, is particularly inflexible, due to the buried nature and is therefore less likely to tolerate mutations without compromising structural and functional integrity. This work therefore suggests that DHPS may well be a good drug target with a new class of drugs interacting with the highly conserved pterin binding site. This would offer substantial advantages over the sulfadrugs that target the more open, variable pABA binding. To this end, they further report the binary complex with the pterin like inhibitor MANIC (14) (Fig. 7) to illustrate the potential for pterinlike inhibitors. MANIC (14) displays all the critical electrostatic interactions of the substrate but the additional $N$-methyl group fits snugly into a small hydrophobic pocket providing further binding affinity compared to the native ligand.

The molecular basis for sulfonamide resistance in DHPS of $S$. pneumoniae has also been further investigated using molecular dynamics (MD) [106]. Simulations were performed both for wild type and mutant strains conferring sulfo- namide resistance in complex with sulfonamide and DHPPP. Interestingly, the two structures display a very different structural response during the MD simulations; the sulfanilamide ligand rearranged to a favourable position for catalysis to occur in the wild type enzyme but was expelled in the mutant during the course of the MD run. The study illustrates the combined role of MD with X-ray analysis to investigate the mechanism of drug resistance that involves rather flexible binding loops and loop motions, pertinent to sulfonamide resistance. Loop motions are a recurring theme within the catalytic mechanisms in the de novo folate enzymes, an understanding of which is conceptually interesting and may further benefit in the design of effective inhibitors.

\section{DHPS Inhibitors}

As discussed, the sulfadrugs have long been known as clinically useful DHPS inhibitors. Although recent years have still seen efforts to improve on these agents, there have been no new clinical agents developed in recent decades. A selection of sulfadrugs is presented in Table $\mathbf{3}$, with reported values for their binding to DHPS from various organisms. Interestingly, the nanomolar affinities reported for dapsone and sulfamethoxazole against mycobacterial strains of DHPS are far more potent that those reported in other microorganisms (usually micromolar) [107]. QSAR studies have been performed on a large number of sulfone and sulfonamide derivatives, showing that the electronic nature of substituents has a significant effect on binding affinity and efficacy [108117]. Sulfones and sulfonamides are still being investigated as inhibitors of the folate pathway. For example, Chio et al. [118] reported the di-halo sulfanilamides $(\mathbf{1 4}$ - 17) had lower 


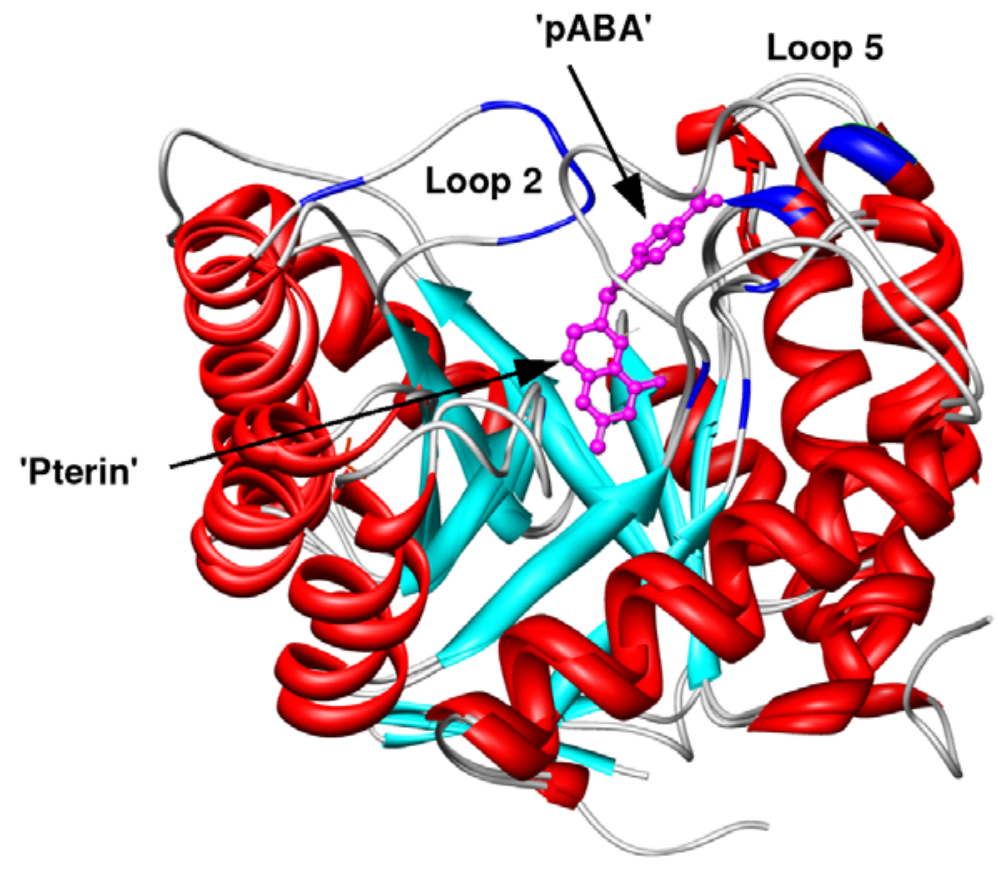

Fig. (7). Superposition of the B. anthracis DHPS structure showing the bound product analog pteroic acid (magenta) and the E. coli structure bound to pterin monophosphate (not shown) structure. Loop mutations that confer sulfonamide resistance [104] are coloured blue on the $E$. coli ribbon.

$\mathrm{IC}_{50}$ values than sulfamethoxazole, particularly for $T$. gondii and P. carinii. Eagon and McManus [119] reported the related, interesting phosphanilic acid (23) as an inhibitor, however there have been no more reports of related phosphonates as inhibitors.

The use of combination therapies has spurred investigations into linked molecules [120-122], incorporating both sulfonamide and pyrimidine subunits to act as inhibitors of both DHPS and DHFR. An early report from Hyde et al. [120], showed that hybrids such as $\mathbf{2 1}$ were potent inhibitors of both DHPS and DHFR, however showed little antibacterial activity, possibly due to problems in cell penetration. More recently, Dhople [121] and Wiese et al. [122], reported very similar compounds (e.g. 22 - 24) which were also potent inhibitors of both DHPS and DHFR, however these molecules showed greater antibacterial activity against $M$. lufu than the corresponding pyrimidine or sulfonamide alone, suggesting cell penetration and possibly a synergistic activity within the cell. In yeast studies sulfa-containing DHPS analogs have been shown to exhibit inhibition of growth and of DHFR [19], while they previously did not inhibit bacteria [18].

The only significant report to date of inhibitors of DHPS that are not close pterin analogs, sulfones or sulfonamides are those of Lever et al. [123-125], who report a range of monocyclic pteridine analogs (isocytosine derivatives), including (MANIC) already mentioned. MANIC (14) is the simplest of these compounds, however Lever et al. [123], investigated a wide range of substituents, predominantly at the 6 position, although a smaller number of substituents at the 5 position were investigated. In general few of these derivatives were more potent than MANIC (14) itself, including derivatives extended from the 6-position (e.g. 24) or with pABA linked onto the nitroso derivative of MANIC (e.g. isocytosine 25). Unfortunately, these inhibitors were not found to inhibit the growth of whole bacterial cells, which may result from them not penetrating the cell membrane.

\section{Addition of Glutamates - the Enzymes FPGS, DHFS and DHFS-FPGS}

The final step in the folate synthesis pathway is the addition of glutamate to dihydropteroate, a reaction catalysed by the enzyme dihydrofolate synthase [E.C. number 6.3.2.12]. Given that DHFS activity is essential for bacteria and is absent in humans, DHFS has the potential to be a target for selective inhibitors. However, targeting DHFS is complicated by the fact that it shares a high degree of similarity with the enzyme, folylpolyglutamate synthase (FPGS) which is found in all organisms. Therefore, in the design of inhibitors for DHFS one needs to consider their effect on FPGS. For example, it would be futile to have an antimicrobial targeting DHFS, only to have it also target FPGS and host folate utilisation.

In some organisms such as E. coli and Neisseria gonorrhoeae addition of L-glutamate to DHF (i.e. DHFS activity) and the subsequent addition of further polyglyutamates (i.e. FPGS activity) are combined and catalysed by a single bifunctional enzyme, DHFS-FPGS, for which there is a recent structure. Although the sequence similarity is high between FPGS and DHFS, there is a growing body of structural evidence to suggest that it may well be feasible to design selective inhibitors against DHFS at least. FPGS may represent a potential target in its own right; compounds targeting FPGS may have utility in preventing cell proliferation and cancers [126-130]. 
Table 3. Selected Sulfadrugs and Binding to DHPS

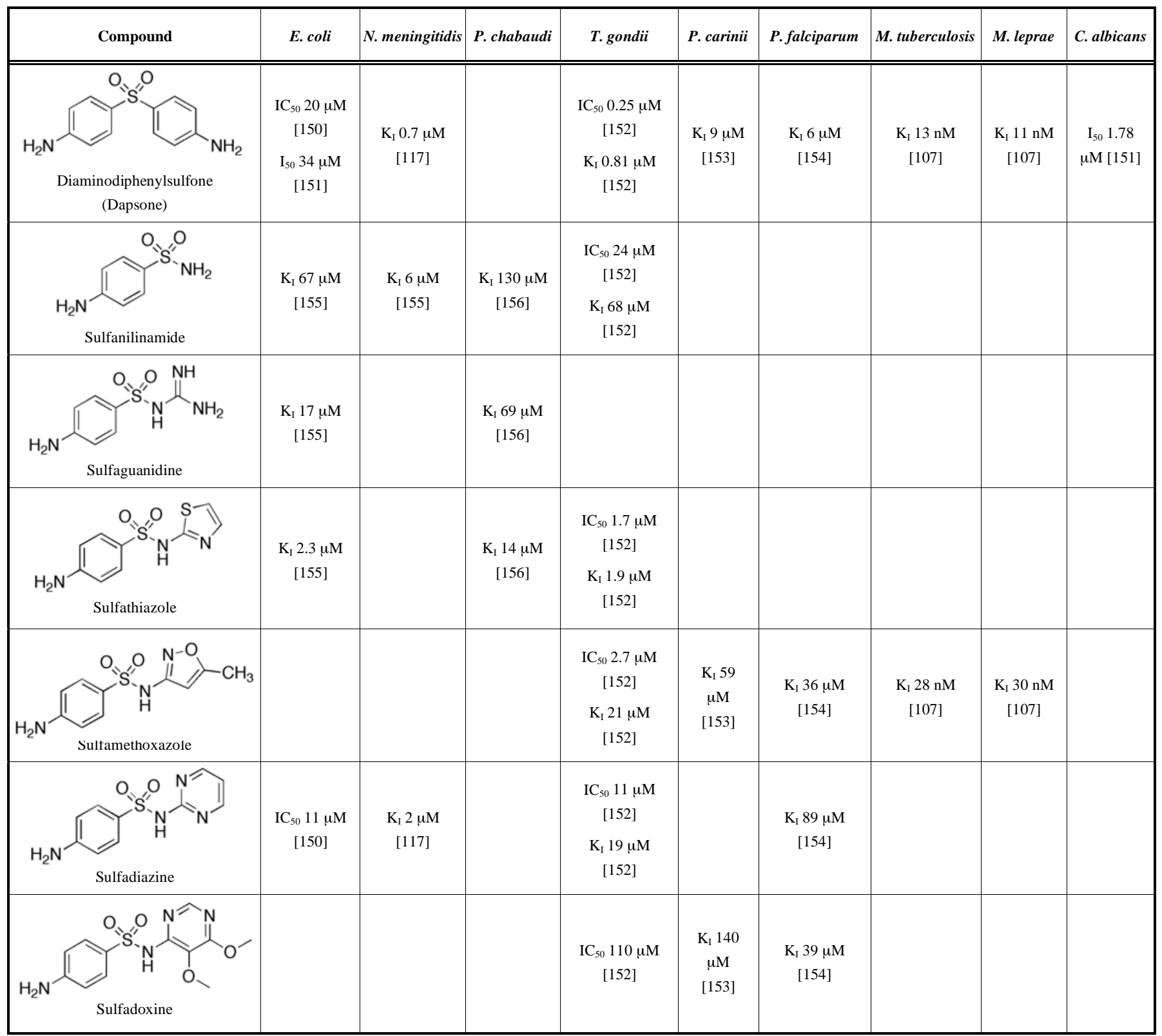

FPGS adds multiple glutamates onto folate to make polyglutamated folates which lack the ability to cross membranes. The number of glutamates can often range from 5-10. Their addition produces a more stable folate that remains within cells. Given the similarity of the substrates of FPGS and DHFS it is perhaps not all that surprising that these enzymes share a high degree of sequence similarity as shown in Fig. (8).

Of considerable interest is the specificity of these enzymes for particular reactions. For example, in humans there is only one enzyme of this class, hFPGS, and it is a specific FPGS since humans don't synthesise their own folate. Likewise the bacterium, L. casei, obtains its folate from milk and only requires an FPGS. However, the protozoal malaria parasite, Plasmodium falciparum is like the bacterium Escherichia coli, in having a single polypeptide enzyme that is bi- functional; the enzyme in these species has both FPGS and DHFS activities.

Yeast on the other hand is different again. It requires both FPGS and DHFS activities but encodes them on two different genes. DHFS is encoded by FOL3 and is essential for viability on normal rich media. FPGS is encoded by MET7 which is essential for methionine biosynthesis and respiratory function. It is also interesting that there is yet another similar protein in $S$. cerevisiae, described as a putative FPGS. Deletion of the gene, YKL132c, encoding this protein does not affect cell growth like the MET7 or FOL3 gene products; the main phenotype is reduced mating.

\section{DHFS and FPGS Structures}

How does an FPGS, a DHFS or an FPGS-DHFS have such narrow or broad specificities? Ways to answer these 
N.g DHFS-FPGS

E.C DHFS-FPGS M.t DHFS-FPGS L.C FPGS Human FPGS S.C FPGS S.C DHFS Pf DHFS-FPGS

N.g DHFS-FPGS E.C DHFS-FPGS M.t DHFS-FPGS L.C FPGS Human FPGS S.C FPGS S.C DHFS P.f DHFS-FPGS

N.g DHFS-FPGS E.C DHFS-FPGS M.t DHFS-FPGS L.C FPGS Human FPGS S.C FPGS S.C DHFS P.f DHFS-FPGS

N.g DHFS-FPGS E.C DHFS-FPGS M.t DHFS-FPGS L.C FPGS Human FPGS S.C FPGS S.C DHFS P.f DHFS-FPGS

N.g DHFS-FPGS E.C DHFS-FPGS M.t DHFS-FPGS L.C FPGS Human FPGS S.C FPGS S.C DHFS P.f DHFS-FPGS

N.g DHFS-FPGS E.C DHFS-FPGS M.t DHFS-FPGS L.C FPGS Human FPGS S.C FPGS S.C DHFS P.f DHFS-FPGS

N.g DHFS-FPGS E.C DHFS-FPGS M.t DHFS-FPGS L.C FPGS Human FPGS S.C FPGS S.C DHFS P.f DHFS-FPGS
- - - - - - - - - - - - - - - - - - - - - - - - - - - - - - - - - - - - - - - - - - - MNS

-----------------------------------------------------------MHKGKKNYPNLI TSFRMNLKKI I LNHDRF SHP ERWKTNALLRFTFVY I KF LFDLMI I KNP $-----------------------M E K N Q N D K S N K N D$ I I HMNDKS GNYDKNN INNF ID -----MI IKRTP QAASP LASWLSYLENLHS-K------TIDLGLERVSLVAARLGVLKPA TNSGPPDSGSATGVVP TPDEIASLLQVEHLLDQRWPETRIDP SLTRISALMDLLGSPQRS ---------- MNYTETVAY I HSFPRLAKT GD HRR-----------ILTLLHALGNPQQQ -----MEYQDAVRMLNTLQTNAGYLEQVKRQRGDPQ--TQLEAMELYLARSGLQVEDLDR LRMVGKTYRDAVTALNSLOSNYANIMA IR-OTGDRKNTMTLLEMHEWSRRIGYSASDFNK 119 -------------------------------------MAIELGLSRITKLLEHLGNP QNS KNDEHDMSD I LHKINNEEKKYEE IKSYSECLELLYKTHALKLGLDNP KKLNESFGHPCDK

$---\mathrm{P}---$
P-VVVVAGTNGKGSVCAYLTQIYKQAG---FKTGTLTSPHLLHYNERIAINAEPVSDDTI 96 PFVFTVAGTNGKGTTCRTLESILMAAG---YKVGVYSSPHLVRYTERVRVQGQELPESAH 105 YPSIHIAGTNGKTSVARMVDALVTALH---RRTGRTTSPHLQSPVERISIDGKP ISPAQY 120 GRYIHVTGINGKGSAANAIAHVLEASG---LTVGLYTSPFIMRFNERIMIDHEP IPDAAL 95 LNI I HVT GTKGKGSTCAFTECILRSYG---LKT GF SSPHLVQVRERIRINGQP ISPELF 110 LNIVHITGTKGKGSTAAFTSSILGQYKEQLPRI GLYTSPHLKSVRERIRINGEP ISEEKF 179 LRVLHIAGTNGKGSVCTYLSSVLQQKS---YQIGKFTTPHLVHVTDSITINNKPIPLERY $\mathbf{8 0}$ YKTIHIAGTNGKGSVCYKIYTCLKIKK---FKVGLFSSPHIFSLRERIIVNDEP ISEKEL 151

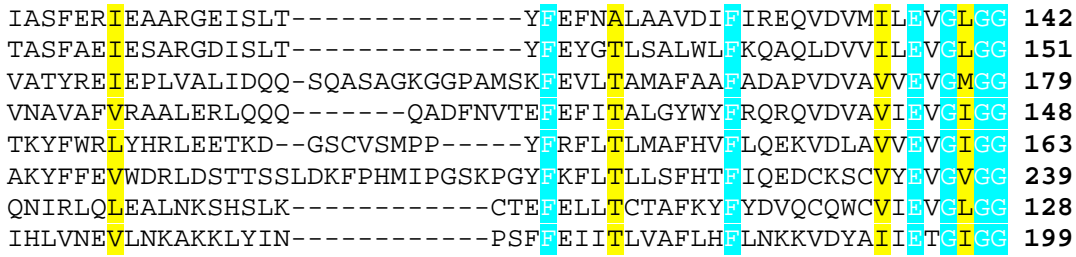

RLDAVNGFD-G--DCAVVTSVDLDHQAFLGDTVEQVGFEKAGVFRSG------KPAICGQ 193 RLDATNIVD-A--DVAVVTSIALDHTDWLGPDRESIGREKAGIFRSE------KPAIVGE 202 RWDATNVIN-A--PVAVITPISIDHVDYLGADIAGIAGEKAGIITRAPDGSPDTVAVIGR 236 DTDSTNVIT-P--VVSVLTEVALDHQKLLGHTTAIAKHKAGIIKRG------IPVVTGN 199 AYDCTNIIRKP--VVCGVSSLGIDHTSLLGDTVEKIAWQKGGIFKQG------VPAFTVL 215 ELDSTNIIEKP--IVCGVTLLGIDHTFMLGDTIEEIAWNKGGIFKSG------APAFTVE 291 RLDATNVIPGANKACCGITKISLDHESFLGNTLSEISKEKAGIITEG------VPFTVID 182 RLDATNILTKP--EVIVITSIGYDHLNILGDNLPIICNEKI GIFKKD------------A 245

NPAPASLVAHAEA IGAKLLMVQRDFEFHAMEN------IQWNYRFRPQHSDGPARNRNAL $2 \mathbf{4}$ PEMP STIADVAQEKGALLQRRGVEWNYSVTD---------HDWAFSDAH--GTLEN---L 248 QVPKVMEVLLAESVRADASVAREDSEFAVLRR-----QIAVGGQVLQLQGLGGVYSDIYL 291 LVPDAAAVVAAKVATTGSQWLRFDRDF SVPKA-----KLHGWGQRFTYEDQDGRISDLEV 254 Q-PEGP LAVLRDRAQQ ISCP LYLCPMLEALEEGGP P LTLGLEGEHQRSNAALALQLAHCW 274 KQPPQGLTILKERAEERKTTLTEVPPFKQLEN----VKLGIAGEFQKSNASLAVMLASEI $\mathbf{3 4 7}$ GTNEASVINVVKERCKALG-----SELSVTDS-------QLNGNMIDTNSWG-CFDLAKL 229 NVVIGP SVAIYKNVFDKAKELNCTIHTVVPEP--------RGERYNEENSRIALRTLEIL 297

----linker---

PFPALRGAYQLSNAACALTVLECLDDRLPVDIGAIKRGLLLVENPG-------RFQVLPG 300 PLPLVP----QPNAATALAALRASG--LEVSENAIRDGIASAILPG-------RFQIVSE 295 PLHGEHQAHNAVLALASVEAFFGAGAQRQLDGDAVRAGFAAVTSPG-------RLERMRS 344 PLVGDYQQRNMAIAIQTAKVYAKQ-TEWPLTPQNIRQGLAASHWPA-------RLEKISD 306 LQRQDRHGAGEPKASRPGLLWQLP LAPVFQP TSHMRLGLRNTEWPG-------RTQVLRR 327 LHTSN------------I LEEKIKCSSNAS IPEKF I I GLQNTKWEG-------RCQVLEK 388 PLNGEYQIFNLRVAMGMLDYLQMN-ELIDITKNEVSTRLAKVDWPGRLYRMDYRFDKVSN 288 NIS-------IDYFLKSIIPIKPP LRIQYLATEQIQH-IKKKFSPD-------NLEHNVQ 342 
Fig. (8). Contd....

$$
\begin{aligned}
& \text { N.g DHFS-FPGS } \\
& \text { E.C DHFS-FPGS } \\
& \text { M.t DHFS-FPGS } \\
& \text { L.C FPGS } \\
& \text { Human FPGS } \\
& \text { S.C FPGS } \\
& \text { S.C DHFS } \\
& \text { P.f DHFS-FPGS }
\end{aligned}
$$

N.g DHFS-FPGS

E.C DHFS-FPGS

M.t DHFS-FPGS

L.C FPGS

Human FPGS

S.C FPGS

S.C DHFS

P.f DHFS-FPGS

N.g DHFS-FPGS

E.C DHFS-FPGS

M.t DHFS-FPGS

L.C FPGS

Human FPGS

S.C FPGS

S.C DHFS

P.f DHFS-FPGS

N.g DHFS-FPGS

E.C DHFS-FPGS

M.t DHFS-FPGS

L.C FPGS

Human FPGS

S.C FPGS

S.C DHFS

P.f DHFS-FPGS

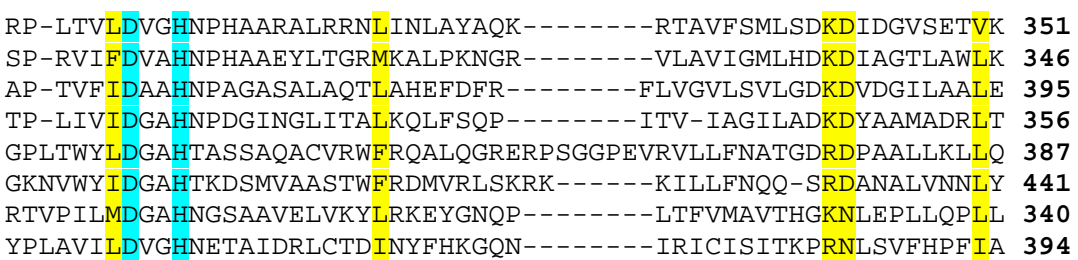

D-----OFDEWYIAP-IDVPRGMTADALKAKIFOHHITNTOTFAVRD-------2-- 393

S------VVDDWYCAP -LEGPRGATAEQL-----LEHLGNGKSFD SVAQ---------- 383

P------VFDSVVVTHN-GSPRALDVEALALAAGERFGPDRVRTAENLRD--------- 438

A------AF STVYLVPVPGTPRALPEAGYEALHEG-------RLKDSWQE--------- 393 P----COFDYAVFCPNLTEVSSTGNADQONFTVTLDOVLLRCLEH--OOHWNHLDEEQA $\mathbf{4 4 0}$ SSVSPEITFDDVIFTTNVTWKSGSYSADLVSMNTSQEDVEKLKVQESLVKNWNKIDDN-- $\mathbf{4 9 9}$ R------PIDQVILTRFNNVEGMPWIHATDPEEIKDF ILTQGYTKEIVIEN-------- 385 QFG---DTLKD IFYLP S LNERTYDFEE IVEMLNNEEE I KNE I KEL I LSSSKKVG------ $\mathbf{4 4 5}$
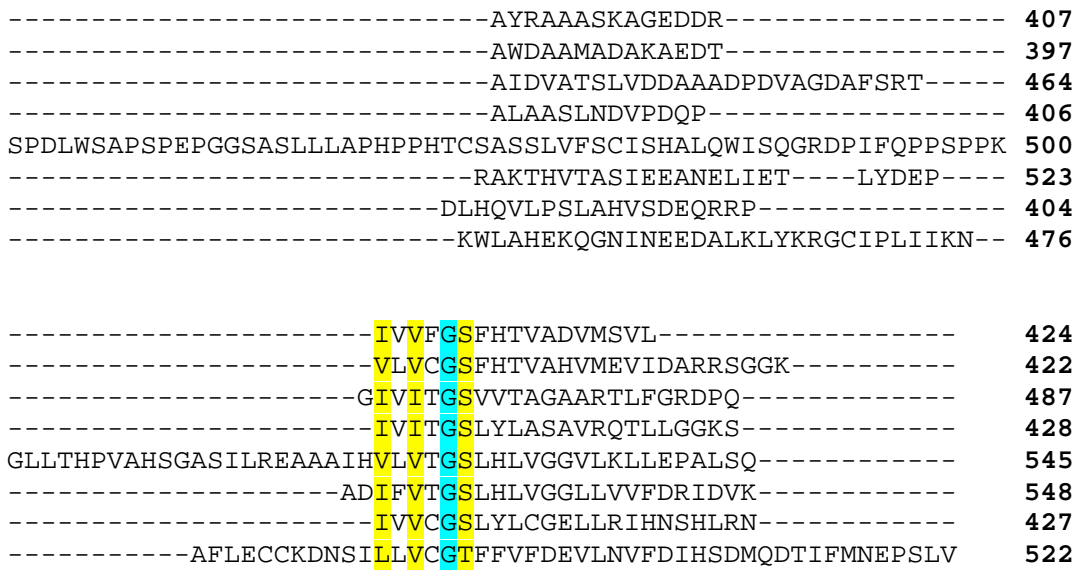

Fig. (8). Multiple sequence alignment of $S$. cerevisiae DHFS against other DHFS and FPGS enzymes. The $S$. cerevisiae DHFS protein sequence is aligned with $S$. cerevisiae FPGS, P. falciparum DHFS-FPGS, L. casei FPGS, E. coli DHFS-FPGS, $N$. gonorrhoeae DHFS-FPGS, Mycobacterium tuberculosis DHFS-FPGS and human FPGS protein sequences using the Biology WorkBench program. The identical residues are highlighted in blue and conservation of strong groups is shown in yellow.

questions may come from detailed structure function studies, mutagenesis and from knowledge of the structures of enzymes from more species. The structures of two FPGSs are now known. The first FPGS structure is from the bacterium L. casei [131, 132], an enzyme without cysteines, a property that may have aided its crytallisation. Although large amounts (tens of milligrams per litre of culture) of biologically active yeast DHFS have been produced [133] none has yet crystallised, due to its aggregation during crystallisation (O. Patel, P. Pilling, R. Fernley, I. Macreadie, unpublished). This may be due to oxidation but it was not prevented by performing the crystallisation under anaerobic conditions or with a reducing agent. Mutagenesis of two "possibly exposed" cysteines as well as carboxylation of the cysteines did not lead to successful production of crystals (O. Patel, P. Pilling, R. Fernley, I. Macreadie, unpublished).

Much understanding of the mode of action of FPGS results from the L casei X-ray structure which has been solved in the apo, the ATP bound forms [131], as the binary with AMPPCP and as the ternary complex with AMPPCP and the preferred monoglutamate folate substrate 5,10-methylenetetrahydrofolate (MTHF) [132]. The structure comprises two domains in which ATP is bound between the two in a chan- nel (Fig. 9b). The protein is modular comprising the ATPbinding $\mathrm{N}$-terminal domain including the commonly found P-loop for phosphate binding, and a novel omega loop that is involved in the folate binding site. The binding of the first substrate (ATP) is not sufficient to create an active enzyme. A rotation of the $C$-terminal domain (Fig. 9b) is needed upon binding of folate which then activates the enzyme to allow the binding of the third substrate, L-glutamate. During this activation process, the adenosine inserts into the 'specificity' pocket and undergoes a change in conformation from a $\mathrm{C}^{2}$ endo to a C3' endo and the base changes from the unusual syn to an anti. Interestingly, the ATP appeared to be further phosphorylated to adenosine tetraphosphate in which the $\delta$ phosphate may be mimicking a tetrahedral carbon intermediate. The putative glutamate-binding site has been further supported by site-directed mutagenesis and kinetic studies [134]. Finally it was noted, based on sequence conservation in the active site regions, that the $L$. casei FPGS structure provides an excellent model for the human enzyme [132].

The structure of the bifunctional bacteria DHFS-FPGS from $E$. coli has been solved from X-ray data (Fig. 9a) [135]. The structure displayed good similarity to the FPGS structure from $L$ casei in the ATP binding site. Notably, the aryl 


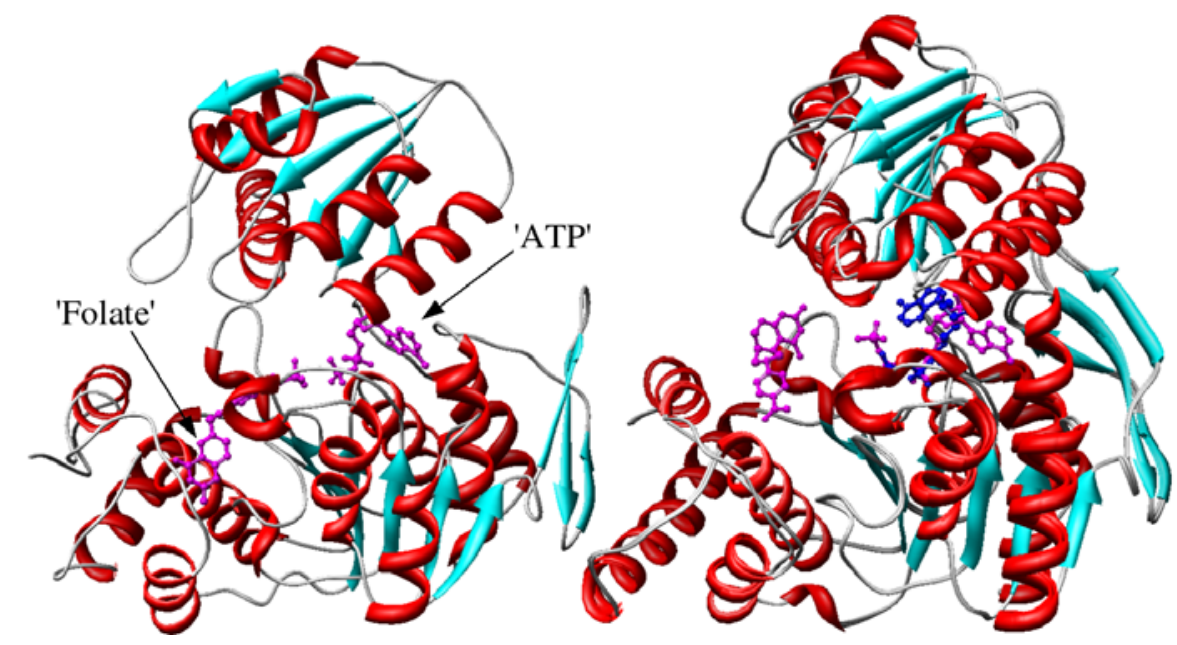

Fig. (9). Ribbon representation of E. coli DHFS-FPGS (left) in complex with ADP and DHP and a superposition of $L$. casei FPGS (right) in the 'inactive', AMPPCP-bound form and the 'active' ternary complex with AMPPCP and MTHF (magenta). The superposition over the $N$ terminal domain illustrates the rotation in the $C$-terminal domain required for activation inactive (blue ligand) to active (magenta).

moiety of the pterin binding site was substantially different between the two and consequently the E. coli structure provides the structural means to look for selective inhibitors of the pterin site.

The pterin binding site during DHFS activity is revealed in the ternary complex of ADP and the phosphorylated intermediate dihydropteroate bound to the E. coli DHFSFPGS. Substantial rearrangements at the active site, or opening of a second pterin site is required in this model to accommodate further glutamate residues that are added to the dihydrofolate substrate. In this manner a structural basis for DHFS and FPGS specificity is thus put forward. A superposition of the $E$. coli DHFS-FPGS and the $L$ case $i$ structure revealed a probable second pterin site some $10 \AA$ distal to the pterin site in E. coli DHFS-FPGS that could accommodate a diglutamate molecule for FPGS activity. Unfortunately, FolC complexes with FPGS bound substrates were not amenable to crystallisation and this remains the current working model. Nevertheless, crystallisation conditions for FPGS from $M$ tuberculosis have recently been reported [136] in the presence of ADP and dihydrofolate.

From a drug discovery perspective, the pteridine in $E$. coli DHFS-FPGS showed high complementarity with the protein active site with all the polar heteroatoms of the pteridine ring involved in either hydrogen bond contacts to the protein or to a bound water. Consequently, the scope for the design of potent inhibitors that interact with the pterin site may be rather limited in terms of chemical diversity [135]. However isosteric modifications in positions 5 and 8 of the ring are well tolerated. Importantly, the pterin pocket in $L$. casei (the human model) is very similar. However the aryl moiety binding site between the two are substantially different, indicating that selective inhibitors can in principal be designed.

\section{DHFS Inhibitors}

Roland et al. [18] showed that the pterin-sulfonamides that are formed as a result of sulfonamides replacing pABA in the reaction catalysed by DHPS bind to and inhibit DHFS. However, they suggest that the concentrations required for effective inhibition are unlikely to be reached in the intracellular environment. There are essentially no specific inhibitors of DHFS reported in the literature, and as such this may present a useful future target.

\section{Multifunctional Enzymes}

Several enzymes of the folate pathway exist as bi or trifunctional complexes, more so in eukaryotes and parasites. Several combinations are currently known (Fig. 10). For example, in fungi, including Candida albicans, Saccharomyces cerevisiae, and $P$. jirovecii, the FAS genes are part of a single open reading frame that encodes a trifunctional, multidomain enzyme that includes DHNA, HPPK and DHPS $[50,137]$. We haven't included the DHFS/FPGS bifunctional ability observed in bacteria: for example, in E. coli DHFS can be thought of as bifunctional 'single enzyme'. The evolutionary drive for multifunctionality has led to the discovery of substrate channelling in many multifunctional enzymes and accordingly efforts to identify channelling mechanisms in the pathway have been undertaken.

Substrate channelling is when the reaction products of one enzyme are actively or passively transferred to another enzyme without escape into the bulk solvent. It occurs in many multi-functional enzyme systems [138] and has potentially several advantages over free diffusion of reaction products within the bulk solvent. These include unfavourable chemical equilibrium and excluding reaction products from competing enzymes. There is a substantial body of structural and biochemical evidence to illustrate the process of channelling substrates through tunnels or electrostatic channels between active sites. For example in the folate utilization steps, the TS-DHFR structure from L. major in complex with methotrexate and NADPH bound at the DHRF site and 5fluoro-2'-deoxyuridylate and 10-propargyl-5,8-dideazafolate bound at TS, shows a strong electrostatic positive potential that forms a surface channel that connects the two sites over the $\sim 40 \AA$ distance.

Two multi-functional enzyme structures from the de novo folate pathway have been structurally characterized: the bifunctional HPPK-DHPS enzyme from $S$. cerevisiae [88] and 


\section{Fungi and yeast}

e.g

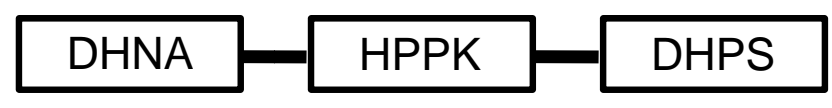

Pneumocystis jiroveci

Saccharomyces cerevisiae

Candida sp

Plants and bacteria

e.g.

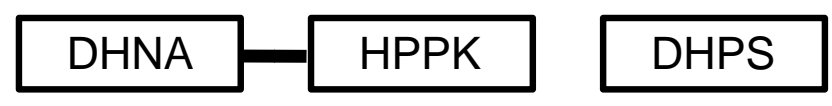

Streptococcus pneumoniae

\section{Plants and protozoa}

e.g.
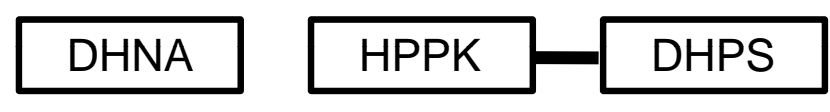

Pisum sativum

riasmivuium $\mathrm{s \mu}$.

Toxoplasma sp.

\section{Bacteria}

e.g.

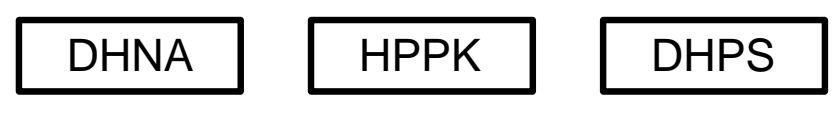

\section{Escherichia coli}

Fig. (10). Some examples of multifunctional enzymes of the folate biosynthesis pathway.

the bifunctional DHNA-HPPK from $S$. pneumoniae [80]. In the former, it was noted that the interfaces do not display the typical characteristics (buried surface area, surface complementarity, hydrophobic content and inter-species conservation) associated with typical protein-protein interactions. The physiological relevance of the domain-domain association was left unresolved and no structural evidence was put forward to be consistent with channelling of substrate from one enzyme to the other in this case.

Similarly, kinetic work [139] based on plant mitochondria is suggestive that substrate channelling in this enzyme combination does not occur. Interestingly, although not important to this review, they also show that DHPS is the key regulating enzyme in the whole pathway. Accordingly they suggest that DHPS may be a good target for folate enhancement in plants.

In the octameric DHNA-HPPK structure (Fig. 3b) [80] the HPPK monomers do not make substantial contacts with DHNA and the stabilizing interaction that orient the HPPK domains are located on the interface within each HPPK tetramer. The active sites face out from each other and no evidence to support either a structural-based or charge-mediated tunnelling pathway of substrate between the two was made. Further evidence against tunnelling or a requirement for coupling was that the activity of DHNA dropped off with time whereas activity of HPPK was maintained, in accord with the belief that HPPK enzymes generally function in the monomeric state; DHNA is clearly multimeric.
We await other structural evidence from the trifunctional enzymes (Fig. 10) to establish whether or not substrate channelling occurs in the enzymes of the de novo folate pathway.

\section{YEAST AND BACTERIAL CELL-BASED METHODS FOR ANALYSIS OF FOLATE SYNTHESIS INHIBI- TORS}

The screening of some organisms for sensitivity to inhibitors of the folate biosynthetic pathway can be difficult or dangerous. For example, with the malaria parasite, Plasmodium falciparum, the culture must take place in blood which contains endogenous folates. This can compromise the assay. Some organisms, such as the pathogen $P$. jirovecii, can't be cultured while others such as Bacillus anthracis are too dangerous to be cultured. In these cases the genes encoding folate biosynthetic enzymes can be cloned and expressed in laboratory strains of Escherichia coli or Saccharomyces cerevisiae in which the endogenous genes have been deleted. The screening of the compounds can therefore be undertaken under simpler and safer conditions.

\section{Yeast Screens}

The major EUROSCARF yeast deletion collection lacks strains deleted for folate synthesis (except in heterozygous diploid knockouts, which retain one copy) since such deletion mutants are regarded as non-viable on rich medium. However, they are only non-viable on regular rich media and can be grown if an appropriate folate (e.g. folinic acid, folic acid) or folate end product (e.g. thymidine monophosphate) 
is added. This is an important observation in the context of screening for potential antifolates since it implies that the inhibition of an antifolate drug can be rescued by the addition of an appropriate folate or folate end product. In addition, some folate precursors may provide rescue of folate synthesis mutants. For example, yeast deleted for DHPS can be rescued by the addition dihydropteroate or dihydrofolate, the product formed by the action of DHFS on dihydropteroate and glutamate. Similarly the deletion of FOL3, the gene encoding DHFS, can be rescued by dihydrofolate, but not by dihydropteroate. Therefore, it is theoretically possible to distinguish between an inhibitor of DHPS and an inhibitor of DHFS by the pattern of rescue. In addition it is possible to rescue by competing with inhibitors. For example, sulfadrugs are classic examples of competitive inhibitors; and their inhibitory effect can be overcome by the addition of $p$ amino benzoic acid [25].

Wild-type yeast strains can also be used for the analysis of folate synthesis inhibitors, however, the high level of endogenous folate synthesis in yeast can make such studies more difficult. Our experience is that wild-type yeast are less sensitive to many existing antimicrobials. With this in mind we would boldly suggest that an antifolate discovered using a yeast model could be even better for a clinical use!

Disruptions of the genes involved in folate synthesis, FOL1 and FOL3, were performed in a tup1 (thymidine monophosphate uptake) mutant strain. The strain employed, TH1, is able to take up thymidine monophosphate, also initially used for the recovery of the mutant deleted for the DFRl gene, which encodes dihydrofolate reductase [140]. Phenotypic analysis of foll and fol3 mutants confirmed that in rich media (YEPD) there was a requirement for thymidine monophosphate, although folinic acid or folic acid can be used [141]. In minimal synthetic media it was established that in addition to the growth requirements inherited from the parental strain, foll and fol3 mutants had additional requirements for methionine, histidine, adenine and thymidine monophosphate [141]. This is consistent with the loss of folate synthesis or utilisation functions. The addition of dihydrofolic acid to minimal media was sufficient to restore growth to foll and fol3 mutants in the absence of any other requirement.

The use of yeast folate synthesis mutants has provided new insights into the mechanism of action of sulfadrugs in that the condensation product of sulfa drug with the pteroate has been shown to be itself inhibitory [19]. This clearly shows that sulfadrugs not only act by competition with pABA, but they have a multiple effect [142]. One target of the sulfa dihydropteroate has been shown to be the folate utilising enzyme, DHFR [143]. Increased production of DHFR led to an increase in resistance to sulfa DHP. However, it is possible that there are additional targets associated with folate utilisation [142].

The construction of yeast strains with mutant DHPS alleles can provide useful information on antifolate resistance. For example, DHPS mutations found in sulfadrug-resistant isolates of the non-culturable fungus Pneumocystis jirovecii, were shown to confer sulfadrug-resistance to $S$. cerevisiae when genetically engineered into the yeast DHPS [28, 144]. Total yeast gene replacement is another option - if a foreign DHPS provides complementation further insights into the mechanisms of drug resistance can be made. For example, loss of DHFS in yeast can be complemented by the Pneumocystis jirovecii DHFS gene [145].

\section{E. coli Screens}

E. coli strains with disruptions in genes involved in folate synthesis are also available. folP mutants have no DHPS, and do not grow on rich media (yeast extract + tryptone) unless thymidine is added. The requirement for thymidine can be complemented by a number of foreign DHPS genes including that from Mycobacterium leprae [107, 146], Mycobacterium tuberculosis [107], P. jirovecii [50], and Plasmodium falciparum [57]. Of particular interest has been complementation by genes involved in sulfa drug resistance. For example, DHPS genes from $P$. jirovecii and Plasmodium falciparum that exhibit various degrees of resistance to sulfamethoxazole and sulfadoxine, have shown levels of sulfamethoxazole and sulfadoxine resistance comparable to the resistance seen in $P$. falciparum and $P$. jirovecii in an $E$. coli folP strain transformed and complemented with these mutant genes [49, 57].

In E. coli, FOLC encodes the bifunctional DHFS-FPGS [147] and the folC mutant can be complemented by the Plasmodium falciparum bifunctional DHFS-FPGS [148]. This mutant strain would therefore appear to have little utility to study a monofunctional DHFS. The remaining enzymes, HPPK and DHNA, are encoded individually in E. coli. They are potentially useful for a range of studies, but have not been exploited to any significant degree as drug targets.

\section{Practicalities in Screens}

From our previous screens on sulfadrugs and other folate synthesis inhibitors we have encountered a number of factors that require consideration lest they upset screens.

- Ensure media and culture vessels have minimal contaminating folate or pABA. Synthetic minimal media that is free of pABA and folic acid can be purchased or made.

- Inoculums should be small because excess cells can provide competing materials such as pABA or folate. It is good to trial a screen with a range of 10-fold seriallydiluted cells; then the concentration of cells where no inhibition occurs can be clearly seen. See Castelli et al. [25].

- Minimise folate levels by pre-growing cells on folatedeficient media. If folate is present cells may grow a significant number of generations before the lack of folate depletes growth. Thus the FA-grown cells may appear to grow almost as well in the absence of folate as in the presence of folate (see Fig. 11).

- It is worth trying a number of strains and species since there can be large variations in uptake and efflux. Permeability mutants are often used in yeast screens but we have not tried to use the usual uptake and efflux mutants. Probably the optimal yeast mutant for screening is one that is dependent on exogenous folate or a folate precursor for two reasons. First there is greater opportunity to competitively inhibit because folate levels will be low, and second, uptake of folate will be occurring so uptake of folate analogs might be expected also. 


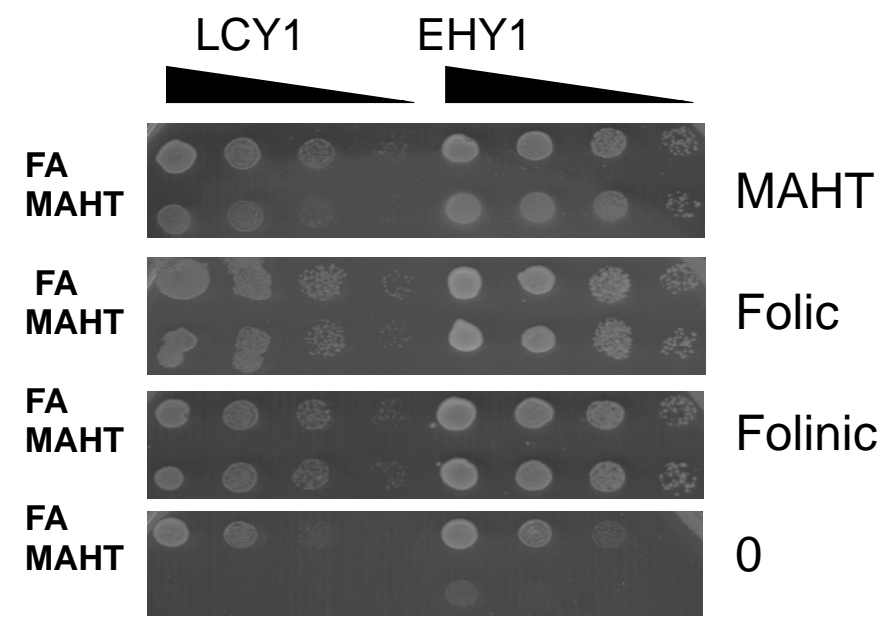

Fig. (11). Cells lacking endogenous folate synthesis (LCY1 lacks DHFS and EHY1 lacks DHPS) were pre-grown on minimal media supplemented with folinic acid (denoted FA) or the folate end products, methionine, adenine, histidine and thymidine monophosphate (denoted MAHT) before inoculation onto solidified minimal medium with MAHT, folic acid, FA or no additive. Cells were serially diluted.

\section{CONCLUSIONS}

Antimicrobial resistance is major threat to our society that has been likened to having an impact on a par with global warming [149]. The World Health Organisation has summed up the situation as "Bad Bugs - no drugs" while the Infectious Diseases Society of America has noted that "As antibiotic discovery stagnates a public health crisis advances". This review has re-examined the folate synthesis where we consider there are new hopes for major new drug discovery initiatives.

Our oldest chemically-synthesised antibiotics, the sulfadrugs, have taught us much about the rise of antibiotic resistance strains. More recently we have made considerable efforts to understand the catalytic and resistance mechanisms down to the molecular level using modern technologies. Such technologies and structural information pave the way for state-of-the-art screening, chemistry and novel in vivo screening methods that employ surrogate organisms, towards the design of selective high affinity inhibitors.

This review has focussed on the antimicrobial targets and our approaches to them. We have particularly addressed a structure-based understanding of the catalytic mechanism and function of the folate biosynthesis enzymes derived from information acquired over the last decade. We believe that this exquisite data resource combined with novel structurebased approaches will deliver inhibitors that will withstand the test of time, replacing the old antifolate drugs that are still widely used.

\section{REFERENCES}

[1] Hill R, Goodwin M. "Prontosil" in treatment of malaria, report of 100 cases. South Med J 1937; 30: 1170-2.

[2] Woods DD. The relationship of $p$-aminobenzoic acid to the mechanism of action of sulphanilamide. Br J Exp Pathol 1940; 21: 74-90.
[3] White PJ, Woods DD. Biochemical properties of staphylococci sensitive and resistant to sulphonamides. J Gen Microbiol 1965; 40: 255-71.

[4] White PJ, Woods DD. The synthesis of $p$-aminobenzoic acid and folic acid by staphylococci sensitive and resistant to sulphonamides. J Gen Microbiol 1965; 40: 243-53.

[5] Brown GM. The biosynthesis of folic acid. II. Inhibition by sulfonamides. J Biol Chem 1962; 237: 536-40.

[6] Pato ML, Brown GM. Mechanisms of resistance of Escherichia coli to sulfonamides. Arch Biochem Biophys 1963; 103: 443-8.

[7] Greenberg J, Richeson EM. Potentiation of the antimalarial activity of sulfadiazine by 2,4-diamino-5-aryloxypyrimidines. J Pharmacol Exp Ther 1950; 99: 444-9.

[8] Hurly MG. Potentiation of pyrimethamine by sulphadiazine in human malaria. Trans R Soc Trop Med Hyg 1959; 53: 412-3.

[9] Michel R. Comparative study of the association of sulfalene and pyrimethamine and of sulfalene alone in mass chemoprophylaxis of malaria. Med Trop (Mars) 1968; 28: 488-94.

[10] Rieckmann KH, Brewer GJ, Powell RD. Effects of diphenylsulphone (dapsone) against Plasmodium vivax of South West Pacific origin. Trans R Soc Trop Med Hyg 1968; 62: 649-53.

[11] Sheehy TW, Reba RC, Neff TA, Gaintner JR, Tigertt WD. Supplemental sulfone (dapsone) therapy. Use in treatment of chloroquine-resistant falciparum malaria. Arch Intern Med 1967; 119: 561-6.

[12] McGregor IA, Williams K, Goodwin LG. Pyrimethamine and sulphadiazine in treatment of malaria. Br Med J 1963; 2: 728-9.

[13] Degowin RL, Powell RD. Drug-resistant falciparum malaria. J Lab Clin Med 1964; 64: 851

[14] Chin W, Contacos PG, Coatney GR, King HK. The evaluation of sulfonamides, alone or in combination with pyrimethamine, in the treatment of multi-resistant falciparum malaria. Am J Trop Med Hyg 1966; 15: 823-9.

[15] Harinasuta T, Viravan C, Reid HA. Sulphormethoxine in chloroquine-resistant falciparum malaria in Thailand. Lancet 1967; 1: $1117-9$.

[16] Chulay JD, Watkins WM, Sixsmith DG. Synergistic antimalarial activity of pyrimethamine and sulfadoxine against Plasmodium falciparum in vitro. Am J Trop Med Hyg 1984; 33: 325-30.

[17] Peters W. Chemotherapy and drug resistance in malaria. New York, NY: Academic Press, Inc. 1987.

[18] Roland S, Ferone R, Harvey RJ, Styles VL, Morrison RW. The characteristics and significance of sulfonamides as substrates for Escherichia coli dihydropteroate synthase. J Biol Chem 1979; 254: 10337-45.

[19] Patel O, Satchell J, Baell J, Fernley R, Coloe P, Macreadie I. Inhibition studies of sulfonamide-containing folate analogs in yeast. Microb Drug Resist 2003; 9: 139-46.

[20] Fermer C, Kristiansen BE, Sköld O, Swedberg G. Sulfonamide resistance in Neisseria meningitidis as defined by site-directed mutagenesis could have its origin in other species. J Bacteriol 1995; 177: 4669-75.

[21] Enne VI, Livermore DM, Stephens P, Hall LM. Persistence of sulphonamide resistance in Escherichia coli in the UK despite national prescribing restriction. Lancet 2001; 357: 1325-8.

[22] Iliades P, Berglez J, Meshnick S, Macreadie I. Promoter strength of folic acid synthesis genes affects sulfa drug resistance in Saccharomyces cerevisiae. Microb Drug Resist 2003; 9: 249-55.

[23] Nichols BP, Guay GG. Gene amplification contributes to sulfonamide resistance in Escherichia coli. Antimicrob Agents Chemother 1989; 33: 2042-8.

[24] Brochet M, Couve E, Zouine M, Poyart C, Glaser P. A. naturally occurring gene amplification leading to sulfonamide and trimethoprim resistance in Streptococcus agalactiae. J Bacteriol 2007.

[25] Castelli LA, Nguyen NP, Macreadie I.G. Sulfa drug screening in yeast: fifteen sulfa drugs compete with $p$-aminobenzoate in Saccharomyces cerevisiae. FEMS Microbiol Lett 2001; 199: 181-4.

[26] Carter JY, Loolpapit MP, Lema OE, Tome JL, Nagelkerke NJ, Watkins WM. Reduction of the efficacy of antifolate antimalarial therapy by folic acid supplementation. Am J Trop Med Hyg 2005; 73: $166-70$.

[27] van Hensbroek MB, Morris-Jones S, Meisner S, Jaffar S, Bayo L, Dackour R, et al. Iron, but not folic acid, combined with effective antimalarial therapy promotes haematological recovery in African 
children after acute falciparum malaria. Trans R Soc Trop Med Hyg 1995; 89: 672-6.

[28] Iliades P, Meshnick SR, Macreadie IG. Dihydropteroate synthase mutations in Pneumocystis jirovecii can affect sulfamethoxazole resistance in a Saccharomyces cerevisiae model. Antimicrob Agents Chemother 2004; 48: 2617-23.

[29] Schrag SJ, Perrot V, Levin BR. Adaptation to the fitness costs of antibiotic resistance in Escherichia coli. Proc Biol Sci 1997; 264: 1287-91.

[30] Bouma JE, Lenski RE. Evolution of a bacteria/plasmid association. Nature 1988; 335: 351-2.

[31] Qvarnström Y, Swedberg G. Additive effects of a two-amino-acid insertion and a single-amino-acid substitution in dihydropteroate synthase for the development of sulphonamide-resistant Neisseria meningitidis. Microbiol 2000; 146: 1151-6.

[32] Fermer C, Swedberg G. Adaptation to sulfonamide resistance in Neisseria meningitidis may have required compensatory changes to retain enzyme function: kinetic analysis of dihydropteroate synthases from $N$. meningitidis expressed in a knockout mutant of Escherichia coli. J Bacteriol 1997; 179: 831-7.

[33] Ansari NA, Kombe AH, Kenyon TA, Mazhani L, Binkin N, Tappero JW, et al. Pathology and causes of death in a series of human immunodeficiency virus-positive and -negative pediatric referral hospital admissions in Botswana. Pediatr Infect Dis J 2003; 22: 437.

[34] Armstrong W, Meshnick S, Kazanjian P. Pneumocystis carinii mutations associated with sulfa and sulfone prophylaxis failures in immunocompromised patients. Microbes Infect 2000; 2: 61-7.

[35] Kovacs JA, Gill VJ, Meshnick S, Masur H. New insights into transmission, diagnosis, and drug treatment of Pneumocystis carinii pneumonia. JAMA 2001; 286: 2450-60.

[36] Meshnick SR. Drug-resistant Pneumocystis carinii. Lancet 1999; 354: 1318-9.

[37] Walzer PD, Foy J, Steele P, Kim CK, White M, Klein RS, et al. Activities of antifolate, antiviral, and other drugs in an immunosuppressed rat model of Pneumocystis carinii pneumonia. Antimicrob Agents Chemother 1992; 36: 1935-42.

[38] Martin JN, Rose DA, Hadley WK, Perdreau-Remington F, Lam PK, Gerberding JL. Emergence of trimethoprim-sulfamethoxazole resistance in the AIDS era. J Infect Dis 1999; 180: 1809-18.

[39] Kazanjian P, Locke AB, Hossler PA, Lane BR, Bartlett MS, Smith JW, et al. Pneumocystis carinii mutations associated with sulfa and sulfone prophylaxis failures in AIDS patients. AIDS 1998; 12: 8738 .

[40] Mei Q, Gurunathan S, Masur H, Kovacs JA. Failure of cotrimoxazole in Pneumocystis carinii infection and mutations in dihydropteroate synthase gene. Lancet 1998; 351: 1631-2.

[41] Ma L, Borio L, Masur H, Kovacs JA. Pneumocystis carinii dihydropteroate synthase but not dihydrofolate reductase gene mutations correlate with prior trimethoprim-sulfamethoxazole or dapsone use. J Infect Dis 1999; 180: 1969-78.

[42] Helweg-Larsen J, Benfield TL, Eugen-Olsen J, Lundgren JD, Lundgren B. Effects of mutations in Pneumocystis carinii dihydropteroate synthase gene on outcome of AIDS-associated $P \mathrm{ca}$ rinii pneumonia. Lancet 1999; 354: 1347-51.

[43] Demanche C, Guillot J, Berthelemy M, Petit T, Roux P, Wakefield AE. Absence of mutations associated with sulfa resistance in Pneumocystis carinii dihydropteroate synthase gene from nonhuman primates. Med Mycol 2002; 40: 315-8.

[44] Visconti E, Ortona E, Mencarini P, et al. Mutations in dihydropteroate synthase gene of Pneumocystis carinii in HIV patients with Pneumocystis carinii pneumonia. Int J Antimicrob Agents 2001; 18: 547-51.

[45] Takahashi T, Hosoya N, Endo T, et al. Relationship between mutations in dihydropteroate synthase of Pneumocystis carinii f. sp hominis isolates in Japan and resistance to sulfonamide therapy. J Clin Microbiol 2000; 38: 3161-4.

[46] Navin TR, Beard CB, Huang L, et al. Effect of mutations in Pneumocystis carinii dihydropteroate synthase gene on outcome of $P$ carinii pneumonia in patients with HIV-1: a prospective study. Lancet 2001; 358: 545-9.

[47] Lane BR, Ast JC, Hossler PA, et al. Dihydropteroate synthase polymorphisms in Pneumocystis carinii. J Infect Dis 1997; 175: 482-5.

[48] Iliades P, Meshnick SR, Macreadie IG. Mutations in the Pneumocystis jirovecii DHPS gene confer cross-resistance to sulfa drugs. Antimicrob Agents Chemother 2005; 49: 741-8.
[49] Iliades P, Meshnick SR, Macreadie IG. Analysis of Pneumocystis jirovecii DHPS alleles implicated in sulfamethoxazole resistance using an Escherichia coli model system. Microbial Drug Resist 2005; 11: 1-8.

[50] Iliades P, Walker DJ, Castelli L, Satchell J, Meshnick SR, Macreadie IG. Cloning of the Pneumocystis jirovecii trifunctional FAS gene and complementation of its DHPS activity in Escherichia coli. Fungal Genet Biol 2004; 41: 1053-62.

[51] Snow RW, Guerra CA, Noor AM, Myint HY, Hay SI. The global distribution of clinical episodes of Plasmodium falciparum malaria. Nature 2005; 434: 214-7.

[52] Brooks DR, Wang P, Read M, Watkins WM, Sims PF, Hyde JE. Sequence variation of the hydroxymethyldihydropterin pyrophosphokinase: dihydropteroate synthase gene in lines of the human malaria parasite, Plasmodium falciparum, with differing resistance to sulfadoxine. Eur J Biochem 1994; 224: 397-405.

[53] Wang P, Brooks DR, Sims PF, Hyde JE. A mutation-specific PCR system to detect sequence variation in the dihydropteroate synthetase gene of Plasmodium falciparum. Mol Biochem Parasitol 1995; 71: 115-25.

[54] Reeder JC, Rieckmann KH, Genton B, Lorry K, Wines B, Cowman AF. Point mutations in the dihydrofolate reductase and dihydropteroate synthetase genes and in vitro susceptibility to pyrimethamine and cycloguanil of Plasmodium falciparum isolates from Papua New Guinea. Am J Trop Med Hyg 1996; 55: 209-13.

[55] Triglia T, Menting JGT, Wilson C, Cowman AF. Mutations in dihydropteroate synthase are responsible for sulfone and sulfonamide resistance in Plasmodium falciparum. Proc Natl Acad Sci USA 1997; 94: 13944-9.

[56] Wang P, Lee CS, Bayoumi R, et al. Resistance to antifolates in Plasmodium falciparum monitored by sequence analysis of dihydropteroate synthetase and dihydrofolate reductase alleles in a large number of field samples of diverse origins. Mol Biochem Parasitol 1997; 89: 161-77.

[57] Berglez J, Iliades P, Sirawaraporn W, Coloe P, Macreadie I. Analysis in Escherichia coli of Plasmodium falciparum dihydropteroate synthase (DHPS) alleles implicated in resistance to sulfadoxine. Int J Parasitol 2004; 34: 95-100.

[58] Dorsey G, Dokomajilar C, Kiggundu M, Staedke SG, Kamya MR, Rosenthal PJ. Principal role of dihydropteroate synthase mutations in mediating resistance to sulfadoxine-pyrimethamine in singledrug and combination therapy of uncomplicated malaria in Uganda. Am J Trop Med Hyg 2004; 71: 758-63.

[59] Zhang Y, Merali S, Meshnick SR. p-aminobenzoic acid transport by normal and Plasmodium falciparum-infected erythrocytes. Mol Biochem Parasitol 1992; 52: 185-94.

[60] Wang P, Wang Q, Sims PF, Hyde JE. Characterisation of exogenous folate transport in Plasmodium falciparum. Mol Biochem Parasitol 2007; 154: 40-51.

[61] Watkins WM, Mosobo M. Treatment of Plasmodium falciparum malaria with pyrimethamine-sulfadoxine: selective pressure for resistance is a function of long elimination half-life. Trans $\mathrm{R}$ Soc Trop Med Hyg 1993; 87: 75-8.

[62] Nzila AM, Nduati E, Mberu EK, et al. Molecular evidence of greater selective pressure for drug resistance exerted by the long-acting antifolate Pyrimethamine/Sulfadoxine compared with the shorteracting chlorproguanil/dapsone on Kenyan Plasmodium falciparum. J Infect Dis 2000; 181: 2023-8.

[63] Wise EM Jr, Abou-Donia MM. Sulfonamide resistance mechanism in Escherichia coli. R plasmids can determine sulfonamideresistant dihydropteroate synthases. Proc Natl Acad Sci USA 1975; 72: $2621-5$

[64] Dallas WS, Gowen JE, Ray PH, Cox MJ, Dev IK. Cloning, sequencing, and enhanced expression of the dihydropteroate synthase gene of Escherichia coli MC4100. J Bacteriol 1992; 174: 5961-70.

[65] Bean DC, Livermore DM, Papa I, Hall LM. Resistance among Escherichia coli to sulphonamides and other antimicrobials now little used in man. J Antimicrob Chemother 2005; 56: 962-4.

[66] Grape M, Sundstrom L, Kronvall G. Sulphonamide resistance gene sul3 found in Escherichia coli isolates from human sources. J Antimicrob Chemother 2003; 52: 1022-4.

[67] Feldman HA. The meningococcus: a twenty-year perspective. Rev Infect Dis 1986; 8: 288-94.

[68] Peltola H. Meningococcal disease: still with us. Rev Infect Dis 1983; 5: 71-91 
[69] Feldman HA. Meningococcal disease, 1965. JAMA 1966; 196: 391-3.

[70] Raadstroem P, Fermer C, Kristiansen B-E, Jenkins A, Sköld O, Swedberg G. Transformational exchanges in the dihydropteroate synthase gene of Neisseria meningitidis: a novel mechanism for acquisition of sulfonamide resistance. J Bacteriol 1992; 174: 638693.

[71] World Health Organization, Control of epidemic meningococcal disease. WHO practical guidelines. 2nd edition 2003.

[72] Fermer C, Qvarnström Y, Swedberg G. Adaptation to sulfonamide resistance in Neisseria meningitidis may have required compensatory changes to retain enzyme function. Kinetic analysis of dihydropteroate synthases from Neisseria meningitidis. Chemistry and biology of pteridines and folates. Proc Int Symp Pteridines and Folates, 11th, Berchtesgaden, Germany, June 15-20, 1997; 449-54.

[73] World Health Organization: Immunization, vaccines and biologicals: Pneumococcal vaccines 2003.

[74] Maskell JP, Sefton AM, Hall LMC. Mechanism of sulfonamide resistance in clinical isolates of Streptococcus pneumoniae. Antimicrob Agents Chemother 1997; 41: 2121-6.

[75] Haasum Y, Strom K, Wehelie R, et al. Amino acid repetitions in the dihydropteroate synthase of Streptococcus pneumoniae lead to sulfonamide resistance with limited effects on substrate $\mathrm{Km}$. Antimicrob Agents Chemother 2001; 45: 805-9.

[76] Xie LJ, Smith JA, Gross SS. GTP cyclohydrolase I inhibition by the prototypic inhibitor 2,4-diamino-6-hydroxypyrimidine - Mechanisms and unanticipated role of GTP cyclohydrolase I feedback regulatory protein. J Biol Chem 1998; 273: 21091-8.

[77] Gabelli SB, Bianchet MA, Xu W, et al. Structure and function of the $E$. coli dihydroneopterin triphosphate pyrophosphatase: a nudix enzyme involved in folate biosynthesis. Structure 2007; 15: 101422.

[78] Hennig M, D'Arcy A, Hampele IC, Page MG, Oefner C, Dale GE. Crystal structure and reaction mechanism of 7,8-dihydroneopterin aldolase from Staphylococcus aureus. Nat Struct Biol 1998; 5: 35762.

[79] Garcon A, Levy C, Derrick JP. Crystal structure of the bifunctional dihydroneopterin aldolase/6-hydroxymethyl-7,8-dihydropterin pyrophosphokinase from Streptococcus pneumoniae. J Mol Biol 2006; 360: 644-53.

[80] Goulding CW, Apostol MI, Sawaya MR, Phillips M, Parseghian A, Eisenberg D. Regulation by oligomerization in a mycobacterial folate biosynthetic enzyme. J Mol Biol 2005; 349: 61-72.

[81] Blaszczyk J, Li Y, Gan J, Yan H, Ji X. Structural basis for the aldolase and epimerase activities of Staphylococcus aureus dihydroneopterin aldolase. J Mol Biol 2007; 368: 161-9.

[82] Haussmann C, Rohdich F, Schmidt E, Bacher A, Richter G. Biosynthesis of pteridines in Escherichia coli. Structural and mechanistic similarity of dihydroneopterin-triphosphate epimerase and dihydroneopterin aldolase. J Biol Chem 1998; 273: 17418-24.

[83] Dittrich S, Mitchell SL, Blagborough AM, et al. An atypical orthologue of 6-pyruvoyltetrahydropterin synthase can provide the missing link in the folate biosynthesis pathway of malaria parasites. Mol Microbiol 2008; 67: 609-18.

[84] Zimmerman M, Tolman RL, Morman H, Graham DW, Rogers EF. Inhibitors of folate biosynthesis. 1. Inhibition of dihydroneopterin aldolase by pteridine derivatives. J Med Chem 1977; 20: 1213-5.

[85] Sanders WJ, Nienaber VL, Lerner CG, et al. Discovery of potent inhibitors of dihydroneopterin aldolase using CrystaLEAD highthroughput X-ray crystallographic screening and structure-directed lead optimization. J Med Chem 2004; 47: 1709-18.

[86] Xiao B, Shi G, Chen X, Yan, H, Ji X. Crystal structure of 6hydroxymethyl-7,8-dihydropterin pyrophosphokinase, a potential target for the development of novel antimicrobial agents. Structure 1999; 7: 489-96.

[87] Hennig, M, Dale GE, D'Arcy A, et al. The structure and function of the 6-hydroxymethyl-7,8-dihydropterin pyrophosphokinase from Haemophilus influenzae. J Mol Biol 1999; 287: 211-9.

[88] Lawrence MC, Iliades P, Fernley RT, Berglez J, Pilling, PA, Macreadie IG. The three-dimensional structure of the bifunctional 6hydroxymethyl-7,8-dihydropterin pyrophosphokinase/dihydropteroate synthase of Saccharomyces cerevisiae. J Mol Biol 2005; 348 : 655-70.

[89] Blaszczyk J, Li Y, Cherry S, et al. Structure and activity of Yersinia pestis 6-hydroxymethyl-7,8-dihydropterin pyrophosphokinase as a novel target for the development of antiplague therapeutics. Acta Crystallogr D Biol Crystallogr 2007; 63: 1169-77.

[90] Blaszczyk J, Shi G, Yan H, Ji X. Catalytic center assembly of HPPK as revealed by the crystal structure of a ternary complex at 1.25 A resolution. Structure 2000; 8: 1049-58.

[91] Stammers DK, Achari A, Somers DO, Bryant PK, Rosemond J, Scott DL, et al. 2.0 A X-ray structure of the ternary complex of 7,8-dihydro-6-hydroxymethylpterinpyrophosphokinase from $E$ scherichia coli with ATP and a substrate analogue. FEBS Lett 1999; 456: 49-53.

[92] Shi G, Blaszczyk J, Ji X, Yan H. Bisubstrate analogue inhibitors of 6-hydroxymethyl-7,8-dihydropterin pyrophosphokinase: Synthesis and biochemical and crystallographic Studies. J Med Chem 2001; 44: 1364-71.

[93] Xiao B, Shi G, Gao J, Blaszczyk J, Liu Q, Ji X, et al. Unusual conformational changes in 6-hydroxymethyl-7,8-dihydropterin pyrophosphokinase as revealed by X-ray crystallography and NMR. J Biol Chem 2001; 276: 40274-81.

[94] Blaszczyk J, Li Y, Shi G, Yan H, Ji X. Dynamic roles of arginine residues 82 and 92 of Escherichia coli 6-hydroxymethyl-7,8dihydropterin pyrophosphokinase: crystallographic studies. Biochem 2003; 42: 1573-80.

[95] Blaszczyk J, Li Y, Wu Y, Shi G, Ji X, Yan H. Essential roles of a dynamic loop in the catalysis of 6-hydroxymethyl-7,8-dihydropterin pyrophosphokinase. Biochemisty 2004; 43: 1469-77.

[96] Blaszczyk J, Shi G, Li Y, Yan H, Ji X. Reaction trajectory of pyrophosphoryl transfer catalyzed by 6-hydroxymethyl-7,8-dihydropterin pyrophosphokinase. Structure 2004; 12: 467-75.

[97] Li Y, Blaszczyk J, Wu Y, Shi G, Ji X, Yan H. Is the critical role of loop 3 of Escherichia coli 6-hydroxymethyl-7,8-dihydropterin pyrophosphokinase in catalysis due to loop-3 residues arginine-84 and tryptophan-89? Site-directed mutagenesis, biochemical, and crystallographic studies. Biochemisty 2005; 44: 8590-9.

[98] Li G, Felczak K, Shi G, Yan H. Mechanism of the conformational transitions in 6-hydroxymethyl-7,8-dihydropterin pyrophosphokinase as revealed by NMR spectroscopy. Biochemisty 2006; 45 : 12573-81.

[99] Swarbrick JD, Buyya S, Gunawardana D, Gayler KR, McLennan AG, Gooley PR. Structure and substrate-binding mechanism of human Ap4A hydrolase. J Biol Chem 2005; 280: 8471-81.

[100] Bermingham A, Bottomley JR, Primrose WU, Derrick JP. Equilibrium and kinetic studies of substrate binding to 6-hydroxymethyl-7,8-dihydropterin pyrophosphokinase from Escherichia coli. J Biol Chem 2000; 275: 17962-7.

[101] Achari A, Somers DO, Champness JN, Bryant PK, Rosemond J, Stammers DK. Crystal structure of the anti-bacterial sulfonamide drug target dihydropteroate synthase. Nat Struct Biol 1997; 4: 4907.

[102] Hampele IC, D'Arcy A, Dale GE, et al. Structure and function of the dihydropteroate synthase from Staphylococcus aureus. J Mol Biol 1997; 268: 21-30.

[103] Baca AM, Sirawaraporn R, Turley S, Sirawaraporn W, Hol WGJ Crystal structure of Mycobacterium tuberculosis 6-hydroxymethyl7,8-dihydropteroate synthase in complex with pterin monophosphate: New insight into the enzymatic mechanism and sulfa-drug action. J Mol Biol 2000; 302: 1193-212.

[104] Babaoglu K, Qi J, Lee RE, White SW. Crystal Structure of 7,8Dihydropteroate synthase from Bacillus anthracis mechanism and novel inhibitor design. Structure 2004; 12: 1705-17.

[105] Vinnicombe HG, Derrick JP. Dihydropteroate synthase from Streptococcus pneumoniae: Characterization of substrate binding order and sulfonamide inhibition. Biochem Biophys Res Comm 1999; 258: 752-7.

[106] Giordanetto F, Fowler PW, Saqi M, Coveney PV. Large scale molecular dynamics simulation of native and mutant dihydropteroate synthase-sulphanilamide complexes suggests the molecular basis for dihydropteroate synthase drug resistance. Philos Transact A Math Phys Eng Sci 2005; 363: 2055-73.

[107] Nopponpunth V, Sirawaraporn W, Greene PJ, Santi DV. Cloning and expression of Mycobacterium tuberculosis and Mycobacterium leprae dihydropteroate synthase in Escherichia coli. J Bacteriol 1999; 181: 6814-21.

[108] Wiese M, Seydel JK, Pieper H, Krueger G, Noll KR, Keck J. Multiple regression analysis of antimalarial activities of sulfones and sulfonamides in cell-free systems and principal component analysis 
to compare with antibacterial activities. Quant Struct Activ Relat 1987; 6: 164-72.

[109] Coats EA, Cordes HP, Kulkarni VM, et al. Multiple regression and principal component analysis of antibacterial activities of sulfones and sulfonamides in whole cell and cell-free systems of various DDS sensitive and resistant bacterial strains. Quantitative Structure-Activity Relationships 1985; 4: 99-109.

[110] De Benedetti PG, Iarossi D, Folli U, Frassineti C, Menziani MC, Cennamo C. Quantitative structure activity relationships in dihydropteroate synthase inhibition by multisubstituted sulfones Design and synthesis of some new derivatives with improved potency. J Med Chem 1989; 32: 2396-9.

[111] De Benedetti PG, Iarossi D, Frassineti C, Menziani MC, Cocchi M, Cennamo C. Comparative QSAR analysis in dihydropteroate synthase inhibition by sulfones. Design and synthesis of some new derivatives with improved potency. Prog Clin Biol Res 1989; 291: 345-8.

[112] Lopez de Compadre RL, Pearlstein RA, Hopfinger AJ, Seydel JK. A quantitative structure-activity relationship analysis of some 4aminodiphenyl sulfone antibacterial agents using linear free energy and molecular modeling methods. J Med Chem 1987; 30: 900-6.

[113] Lopez de Compadre RL, Pearlstein RA, Hopfinger AJ, Seydel JK. A quantitative structure-activity relationship analysis of some 4aminodiphenyl sulfone antibacterial agents using linear free energy and molecular modeling methods [Erratum to Ref. 112]. J Med Chem 1988; 31: 2315.

[114] Hopfinger AJ, Lopez de Compadre RL, Koehler MG, Emery S, Seydel JK. An extended QSAR analysis of some 4-aminodiphenylsulfone antibacterial agents using molecular modeling and LFE-relationships. Quant Struct Activ Relation 1987; 6: 111-17.

[115] Koehler MG, Hopfinger AJ, Seydel JK. A comparison of QSARs proposed for the inhibition of dihydropteroate synthase by substituted 4-aminodiphenylsulfones. J Mol Struct 1988; 179: 319-32.

[116] De Benedetti PG, Iarossi D, Menziani C, Caiolfa V, Frassineti C, Cennamo C. Quantitative structure-activity analysis in dihydropteroate synthase inhibition of sulfones. Comparison with sulfanilamides. J Med Chem 1987; 30: 459-64.

[117] Ho RI, Corman L, Morse SA, Schneider H. Structure-activity of sulfones and sulfonamides on dihydropteroate synthetase from Neisseria meningitidis. Antimicrob Agents Chemother 1975; 7: 758-63.

[118] Chio L-C, Bolyard LA, Nasr M, Queener SF. Identification of a class of sulfonamides highly active against dihydropteroate synthase from Toxoplasma gondii, Pneumocystis carinii, and Mycobacterium avium. Antimicrob Agents Chemother 1996; 40: 727-33.

[119] Eagon RG, McManus AT. Phosphanilic acid inhibits dihydropteroate synthase. Antimicrob Agents Chemother 1989; 33: 1936-8.

[120] Hyde RM, Paterson RA, Beddell CR, et al. The activity of sulfonamide-substituted benzylpyrimidines against dihydropteroate synthase, dihydrofolate reductase, and bacterial cell cultures. Chem. Biol. Pteridines, Proc. Int. Symp. Pteridines Folic Acid Deriv.: Chem Biol Clin Aspects 7th 1983; 505-9.

[121] Dhople AM. In vitro and in vivo activity of K-130, a dihydrofolate reductase inhibitor, against Mycobacterium leprae. Arzneimittelforschung 1999; 49: 267-71.

[122] Wiese M, Schmalz D, Seydel JK. New antifolate 4,4'-diaminodiphenyl sulfone substituted 2,4-diamino-5-benzylpyrimidines. Proof of their dual mode of action and autosynergism. Arch Pharm Weinheim 1996; 329: 161-8.

[123] Lever OW Jr, Bell LN, McGuire HM, Ferone R. Monocyclic pteridine analogs. Inhibition of Escherichia coli dihydropteroate synthase by 6-amino-5-nitrosoisocytosines. J Med Chem 1985; 28: 18704.

[124] Lever OW Jr, Hyman C, Ray PH, Ferone R, Kelsey JE. A galactoside derivative of a nitrosoisocytosine inhibitor of dihydropteroate synthase: synthesis and biological evaluation. J Heterocycl Chem 1986; 23: 629-31.

[125] Lever OW Jr, Bell LN, Hyman C, McGuire HM, Ferone R. Inhibitors of dihydropteroate synthase: substituent effects in the sidechain aromatic ring of 6-[[3-(aryloxy)propyl]amino]-5-nitrosoisocytosines and synthesis and inhibitory potency of bridged 5nitrosoisocytosine-p-aminobenzoic acid analogs. J Med Chem 1986; 29: 665-70.

[126] Clarke L, Rosowsky A, Waxman DJ. Inhibition of human liver folylpolyglutamate synthetase by non-gamma-glutamylatable antifolate analogs. Mol Pharmacol 1987; 31: 122-7.
[127] DeMartino JK, Hwang I, Xu L, Wilson IA, Boger DL. Discovery of a potent, nonpolyglutamatable inhibitor of glycinamide ribonucleotide transformylase. J Med Chem 2006; 49: 2998-3002.

[128] Leil TA, Endo C, Adjei AA, et al. Identification and characterization of genetic variation in the folylpolyglutamate synthase gene. Cancer Res 2007; 67: 8772-82.

[129] Rosowsky A, Forsch RA, Reich VE, Freisheim JH, Moran RG. Side chain modified 5-deazafolate and 5-deazatetrahydrofolate analogues as mammalian folylpolyglutamate synthetase and glycinamide ribonucleotide formyltransferase inhibitors: synthesis and in vitro biological evaluation. J Med Chem 1992; 35: 1578-88.

[130] Wettergren Y, Odin E, Nilsson S, Willen R, Carlsson G, Gustavsson B. Low expression of reduced folate carrier-1 and folylpolyglutamate synthase correlates with lack of a deleted in colorectal carcinoma mRNA splice variant in normal-appearing mucosa of colorectal carcinoma patients. Cancer Detect Prev 2005; 29: 348-55.

[131] Sun X, Bognar AL, Baker EN, Smith CA. Structural homologies with ATP- and folate-binding enzymes in the crystal structure of folylpolyglutamate synthetase. Proc Natl Acad Sci USA 1998; 95 : 6647-52.

[132] Sun X, Cross JA, Bognar AL, Baker EN, Smith CA. Folate-binding triggers the activation of folylpolyglutamate synthetase. J Mol Biol 2001; 310: 1067-78.

[133] Patel O, Fernley R, Macreadie I. Saccharomyces cerevisiae expression vectors with thrombin-cleavable $\mathrm{N}$ - and C-terminal 6x(His) tags. Biotechnol Lett 2003; 25: 331-4.

[134] Sheng Y, Sun X, Shen Y, Bognar AL, Baker EN, Smith CA. Structural and functional similarities in the ADP-forming amide bond ligase superfamily: implications for a substrate-induced conformational change in folylpolyglutamate synthetase. J Mol Biol 2000; 302: 425-38.

[135] Mathieu M, Debousker G, Vincent S, Viviani F, Bamas-Jacques N, Mikol V. Escherichia coli FolC structure reveals an unexpected dihydrofolate binding site providing an attractive target for antimicrobial therapy. J Biol Chem 2005; 280: 18916-22.

[136] Young PG, Smith CA, Sun X, Baker EN, Metcalf P. Purification, crystallization and preliminary X-ray analysis of Mycobacterium tuberculosis folylpolyglutamate synthase (MtbFPGS). Acta Crystallogr F 2006; 62: 579-82.

[137] Volpe F, Ballantine SP, Delves CJ. The multifunctional folic acid synthesis fas gene of Pneumocystis carinii encodes dihydroneopterin aldolase, hydroxymethyldihydropterin pyrophosphokinase and dihydropteroate synthase. Eur J Biochem 1993; 216: 449-58.

[138] Then RL. History and future of antimicrobial diaminopyrimidines. J Chemother 1993; 5: 361-8.

[139] Mouillon JM, Ravanel S, Douce R, Rebeille F. Folate synthesis in higher-plant mitochondria: coupling between the dihydropterin pyrophosphokinase and the dihydropteroate synthase activities. Biochem J 2002; 363: 313-9.

[140] Huang T, Barclay BJ, Kalman TI, von Borstel RC, Hastings PJ. The phenotype of a dihydrofolate reductase mutant of Saccharomyces cerevisiae. Gene 1992; 121: 167-71.

[141] Bayly AM, Berglez JM, Patel O, et al. Folic acid utilisation related to sulfa drug resistance in Saccharomyces cerevisiae. FEMS Microbiol Lett 2001; 204: 387-90.

[142] Patel OG, Mberu EK, Nzila AM, Macreadie IG. Sulfa drugs strike more than once. Trends Parasitol 2004; 20: 1-3.

[143] Patel O, Karnik K, Macreadie IG. Over-production of dihydrofolate reductase leads to sulfa-dihydropteroate resistance in yeast. FEMS Microbiol Lett 2004; 236: 301-5.

[144] Meneau I, Sanglard D, Bille J, Hauser PM. Pneumocystis jirovecii dihydropteroate synthase polymorphisms confer resistance to sulfadoxine and sulfanilamide in Saccharomyces cerevisiae. Antimicrob Agents Chemother 2004; 48: 2610-6.

[145] Hauser PM, Lo Presti L, Cockell M, Cerutti L, Simanis V. Analysis of Pneumocystis carinii gene function by complementation in yeast mutants. J Eukaryotic Microbiol 2006; 53: S149-S50.

[146] Williams DL, Spring L, Harris E, Roche P, Gillis TP. Dihydropteroate synthase of Mycobacterium leprae and dapsone resistance. Antimicrob Agents Chemother 2000; 44: 1530-7.

[147] Bognar AL, Osborne C, Shane B, Singer SC, Ferone R. Folylpoly$\gamma$-glutamate synthetase-dihydrofolate synthetase. Cloning and high expression of the Escherichia coli folC gene and purification and properties of the gene product. J Biol Chem 1985; 260: 5625-30.

[148] Salcedo E, Cortese JF, Plowe CV, Sims PF, Hyde JE. A bifunctional dihydrofolate synthetase--folylpolyglutamate synthetase in 
Plasmodium falciparum identified by functional complementation in yeast and bacteria. Mol Biochem Parasitol 2001; 112: 239-52.

[149] Tapsall J, Merlino J. Towards an integrated approach to the problem of antimicrobial resistance in Australia. Microbiol Aust 2007; 28: 152-3.

[150] McCullough JL, Maren TH. Inhibition of dihydropteroate synthetase from Escherichia coli by sulfones and sulfonamides. Antimicrob Agents Chemother 1973; 3: 665-9.

[151] Otzen T, Wempe EG, Kunz B, et al. Folate-synthesizing enzyme system as target for development of inhibitors and inhibitor combinations against Candida albicans-Synthesis and biological activity of new 2,4-diaminopyrimidines and 4'-substituted 4-aminodiphenyl sulfones. J Med Chem 2004; 47: 240-53.

[152] Allegra CJ, Boarman D, Kovacs JA, et al. Interaction of sulfonamide and sulfone compounds with Toxoplasma gondii dihydropteroate synthase. J Clin Invest 1990; 85: 371-9.
[153] Merali S, Zhang Y, Sloan D, Meshnick S. Inhibition of Pneumocystis carinii dihydropteroate synthetase by sulfa drugs. Antimicrob Agents Chemother 1990; 34: 1075-8.

[154] Zhang Y, Meshnick SR. Inhibition of Plasmodium falciparum dihydropteroate synthetase and growth in vitro by sulfa drugs. Antimicrob Agents Chemother 1991; 35: 267-71.

[155] Poe M. Antibacterial synergism: a proposal for chemotherapeutic potentiation between trimethoprim and sulfamethoxazole. Science 1976; 194: 533-5.

[156] Walter RD, Koenigk E. Biosynthesis of folic acid compounds in Plasmodia. Purification and properties of the 7,8-dihydropteroatesynthesizing enzyme from Plasmodium chabaudi. Hoppe Seyler's Z Physiol Chem 1974; 355: 431-7.

Received: March 14, 2008

Revised: April 09, 2008

Accepted: April 10, 2008

(C) Swarbrick et al; Licensee Bentham Open.

This is an open access article distributed under the terms of the Creative Commons Attribution License (http://creativecommons.org/licenses/by/2.5/), which permits unrestrictive use, distribution, and reproduction in any medium, provided the original work is properly cited. 